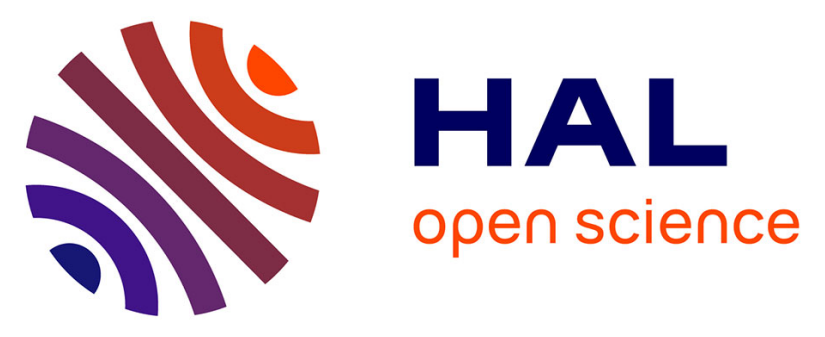

\title{
Moderate chronic ethanol consumption exerts beneficial effects on nonalcoholic fatty liver in mice fed a high-fat diet possible role of higher formation of triglycerides enriched in monounsaturated fatty acids
}

Simon Bucher, Karima Begriche, Daniel D. Catheline, Viviane Trak-Smayra, François Tiaho, Cédric Coulouarn, Gregory Pinon, Dominique Lagadic-Gossmann, Vincent V. Rioux, Bernard Fromenty

\section{- To cite this version:}

Simon Bucher, Karima Begriche, Daniel D. Catheline, Viviane Trak-Smayra, François Tiaho, et al.. Moderate chronic ethanol consumption exerts beneficial effects on nonalcoholic fatty liver in mice fed a high-fat diet possible role of higher formation of triglycerides enriched in monounsaturated fatty acids. European Journal of Nutrition, 2020, 59 (4), pp.1619-1632. 10.1007/s00394-019-02017-1 . hal-02152865

\section{HAL Id: hal-02152865}

https://hal-univ-rennes1.archives-ouvertes.fr/hal-02152865

Submitted on 8 Jul 2019

HAL is a multi-disciplinary open access archive for the deposit and dissemination of scientific research documents, whether they are published or not. The documents may come from teaching and research institutions in France or abroad, or from public or private research centers.
L'archive ouverte pluridisciplinaire HAL, est destinée au dépôt et à la diffusion de documents scientifiques de niveau recherche, publiés ou non, émanant des établissements d'enseignement et de recherche français ou étrangers, des laboratoires publics ou privés. 
1 Moderate chronic ethanol consumption exerts beneficial effects on nonalcoholic fatty liver in

2 mice fed a high-fat diet. Possible role of higher formation of triglycerides enriched in monounsaturated fatty acids

5 Simon Bucher ${ }^{1}$, Karima Begriche ${ }^{1}$, Daniel Catheline ${ }^{2}$, Viviane Trak-Smayra ${ }^{3}$, François Tiaho ${ }^{4}$,

6 Cédric Coulouarn ${ }^{1}$, Grégory Pinon ${ }^{1}$, Dominique Lagadic-Gossmann ${ }^{4}$, Vincent Rioux ${ }^{2}$, Bernard $7 \quad$ Fromenty $^{1}$

8

$9 \quad{ }^{1}$ Univ Rennes, Inserm, Inra, Institut NUMECAN (Nutrition Metabolisms and Cancer) - UMR_S 10 1241, UMR_A 1341, F-35000 Rennes, France

11 22Laboratoire de Biochimie-Nutrition Humaine, Agrocampus Ouest, Rennes, France

$12 \quad{ }^{3}$ Pathology Department, Saint-Joseph University, Beirut, Lebanon

$13{ }^{4}$ Univ Rennes, Inserm, EHESP, Irset (Institut de recherche en santé, environnement et travail) 14 UMR_S 1085, F-35000 Rennes, France

16 Correspondence should be addressed to Bernard Fromenty; bernard.fromenty@inserm.fr 


\section{Abstract}

Purpose: Several clinical studies suggested that light-to-moderate alcohol intake could alleviate nonalcoholic fatty liver disease (NAFLD), but the underlying mechanism is still poorly understood.

Methods: Mice fed a high-fat diet (HFD) were submitted or not to moderate ethanol intake for 3 months (ca. $10 \mathrm{~g} / \mathrm{kg} /$ day) via the drinking water. Biochemical, analytical and transcriptomic analyses were performed in serum and liver.

Results: Serum ethanol concentrations in ethanol-treated HFD mice were comprised between 0.5 and $0.7 \mathrm{~g} / \mathrm{l}$ throughout the experiment. NAFLD improvement was observed in ethanol-treated HFD mice as assessed by reduced serum transaminase activity. This was associated with less microvesicular and more macrovacuolar steatosis, the absence of apoptotic hepatocytes and a trend towards less fibrosis. Liver lipid analysis showed increased amounts of fatty acids incorporated in triglycerides and phospholipids, reduced proportion of palmitic acid in total lipids and higher desaturation index, thus suggesting enhanced stearoyl-coenzyme A desaturase activity. mRNA expression of several glycolytic and lipogenic enzymes was upregulated. Genome-wide expression profiling and gene set enrichment analysis revealed an overall downregulation of the expression of genes involved in collagen fibril organization and leukocyte chemotaxis and an overall upregulation of the expression of genes involved in oxidative phosphorylation and mitochondrial respiratory chain complex assembly. In addition, mRNA expression of several proteasome subunits was upregulated in ethanol-treated HFD mice.

Conclusions: Moderate chronic ethanol consumption may alleviate NAFLD by several mechanisms including the generation of non-toxic lipid species, reduced expression of profibrotic and proinflammatory genes, restoration of mitochondrial function and possible stimulation of proteasome activity.

Keywords: Ethanol, NAFLD, Liver, Mouse, Lipids, Transcriptomics 


\section{Introduction}

Alcohol abuse is associated with a large array of ailments including liver diseases, psychiatric disorders, cardiomyopathy and pancreatitis [1, 2]. Regarding the liver, sustained high alcohol consumption (>20 and 30 grams/day of alcohol for women and men, respectively) almost always leads to steatosis, which can then progress in some patients to steatohepatitis, cirrhosis and hepatocellular carcinoma [2, 3]. Importantly, a recent systematic analysis of data providing from 195 different countries and territories indicated that alcohol drinking, regardless of amount, actually increases the overall risk to health across population [4]. However, the latter study and others found some protective effects of light-to-moderate alcohol consumption (i.e. $<20$ and 30 grams/day of alcohol for women and men, respectively) on ischemic heart disease and diabetes [4-6]. Moreover, several clinical studies suggested that light-to-moderate alcohol intake could have beneficial effects on nonalcoholic fatty liver disease (NAFLD) [7-12], which is commonly associated with obesity. For instance, light-to-moderate alcohol consumption has been reported to reduce the degree of fatty liver [10], the levels of serum transaminases [11, 12] and the risk of developing nonalcoholic steatohepatitis (NASH) [7, 8, 11, 12], which is characterized by the presence of necroinflammation and fibrosis, in addition to fatty liver. However, as pointed out by some authors, clinical data reporting these beneficial effects on NAFLD should be interpreted with caution because of the existence of several potential sources of bias, confounding factors and errors [7, 11]. Moreover, other studies reported no beneficial effects of moderate alcohol drinking on NAFLD [12-14]. For example, a 47-month longitudinal cohort study reported that modest alcohol use was associated with less improvement in steatosis and blood level of aspartate aminotransferase (AST), compared with no alcohol consumption [13], while a Mendelian randomization study showed that moderate 
alcohol consumption had no beneficial effect on hepatic steatosis and necroinflammatory activity [14].

Only 4 experimental studies carried out in rodents previously reported the beneficial effects of light-to-moderate intake of alcohol on NAFLD [15-18]. In 2009, we first reported that moderate ethanol consumption for 6 months reduced the gain of body weight, liver triglycerides and diabetes in leptin-deficient obese and diabetic ob/ob mice [15]. However, these beneficial effects were not associated with reduced levels of plasma transaminases. A recent study also carried out in ob/ob mice reported that moderate alcohol intake for 6 weeks decreased plasma levels of alanine aminotransferase (ALT) and AST, liver triglycerides and hepatic inflammation [16]. Investigations performed in rats fed a high-fat diet (HFD) reported that low ethanol consumption for 12 weeks lessened serum levels of ALT and lactate dehydrogenase (LDH), whereas liver triglycerides were unchanged [17]. Finally, investigations in rats fed a high-fat high-cholesterol diet showed that a moderate ethanol consumption for 8 weeks alleviated liver fibrosis and reduced the mRNA expression of several profibrotic genes [18]. Notably, the beneficial effects of moderate ethanol exposure in rodents are not restricted to the liver and can also be observed in other organs and tissues such heart, colon, white adipose tissue and blood vessels [19-21]. Lower oxidative stress and inflammation as well as improvement of lipid metabolism could be involved in these favorable effects [19-21].

The mechanism(s) whereby light-to-moderate alcohol consumption could be beneficial on NAFLD is poorly understood. Hence, the aim of our study was to improve our knowledge regarding these mechanism(s) by carrying out investigations in HFD obese mice submitted or not to moderate ethanol intake (ca. $10 \mathrm{~g} / \mathrm{kg} /$ day) for 3 months via the drinking water. In particular, we performed a thorough histological examination of livers associated for the first time with hepatic fatty acid analysis and unsupervised genome-wide expression profiling. 


\section{Materials and Methods}

\section{Animals and ethanol administration}

Thirty 7-week-old male C57BL/6J-+/+ mice, weighing 20 to 23 g, were purchased from Janvier (Le-Genest-St-Isle, France). After arrival, the mice were acclimatized in the animal care facility of the University of Rennes 1 (ARCHE), accredited by the French veterinary authorities (agreement $\mathrm{n}^{\circ} \mathrm{A} 35$ 23840) and fed ad libitum on a standard diet (SD) bringing $3 \mathrm{kcal} / \mathrm{g}$ of food (Teklad global 16\% protein rodent diet, ENVIGO, Huntingdon, United Kingdom). After 1 week of acclimatization, mice were split into three groups of 10 animals. While one group was kept on the SD, the two others were fed a 60\% high-fat diet (HFD) bringing $5.5 \mathrm{kcal} / \mathrm{g}$ (260HF V19, Safe Diet, Augy, France). In this diet, $60 \%$ of the energy came from lipids, mainly anhydrous milk fat with $233 \mathrm{~g} / \mathrm{kg}$ of saturated fatty acids (SFAs). The main nutrient composition of these diets is given in the Supplementary table 1. Details regarding the protocol of ethanol exposure (ca. $10 \mathrm{~g} / \mathrm{kg} / \mathrm{day}$ corresponding to $15.9 \%$ of calories from alcohol) and blood withdrawal are provided in the Supplementary methods 1 .

\section{Serum analyses}

Immediately after collection, blood was centrifuged for $10 \mathrm{~min}$ at $1000 \mathrm{~g}$ and serum was immediately used for most biochemical analyses, or stored at $-80^{\circ} \mathrm{C}$ until use for insulin and adiponectin measurement. Activity of alanine aminotransferase (ALT) and aspartate aminotransferase (AST), total cholesterol, triglycerides and glucose levels was measured on an automatic analyzer (Cobas 8000, Roche Diagnostics, Mannheim, Germany) using the appropriate reagents purchased from Roche Diagnostics. Total antioxidant capacity was assessed using the Biovision TAC Colorimetric Assay Kit (K274-100, Milpitas, CA). Ethanol levels were measured using the Ethanol assay kit purchased from Abcam (Paris, France). Insulin and adiponectin were 
respectively determined using the Ultra-Sensitive Insulin Mouse ELISA Kit and the Adiponectin Mouse ELISA kit purchased from Crystal Chem (Downers Grove, IL).

\section{Liver histology and fibrosis quantification}

To evaluate steatosis, necroinflammation, apoptosis and fibrosis, liver fragments were fixed in $4 \%$ neutral formalin and embedded in paraffin. Then, $4 \mu \mathrm{m}$ thick sections were cut and stained with hematoxylin-eosin-safran (HES) or Sirius red. The sections were then digitally scanned with the NanoZoomer 2.0 RS (Hamamatsu Corp. Japan) and thoroughly examined by an experienced pathologist (V.T.-S.). The degree of hepatic steatosis was evaluated in 10 different randomly chosen fields (x 200) as the percentage of hepatocytes containing one or several lipid vacuoles. The classification of steatosis into 3 different categories (i.e. microvesicular, mediovesicular and macrovacuolar) was determined as previously described [22, 23]. Necroinflammation, portal fibrosis and perisinusoidal fibrosis were evaluated on the entire slide and scored 0 (absent), 1 (mild) or 2 (moderate), as previously reported [23]. Finally, apoptosis was scored 0 (absent) or 1 (present) depending on the presence of apoptotic bodies in the hepatic parenchyma.

In order to have more information regarding fibrosis, deposition of fibrillary collagen was assessed by using second-harmonic generation (SHG) microscopy available at the light microscopyimaging center (MRic facility of Biosit, University of Rennes 1), as previously described [24, 25]. More details on the SHG methodology used in our study are provided in the Supplementary methods 2 .

\section{Activity of respiratory chain complexes I and II in liver}

For protein extraction, liver samples were rinsed in phosphate-buffered saline (PBS) and then lysed using a Dounce homogenizer with the extraction buffer supplied by Abcam, as recommended by the 
manufacturer. Mitochondrial respiratory chain (MRC) complex I activity was measured with $5 \mu \mathrm{g}$ of liver proteins by using the Complex I Enzyme Activity Dipstick Assay kit from Abcam (Paris, France), as recently described [26, 27]. Activity of the MRC complex II, also referred to as succinate dehydrogenase (SDH), was measured with $100 \mu \mathrm{g}$ of liver proteins using the Complex II Enzyme Activity Microplate Assay kit from Abcam, as recently reported [26, 27].

\section{Hepatic glutathione, carbonylated proteins, lipid peroxidation and CYP2E1 protein} expression

Reduced (GSH) and oxidized (GSSG) glutathione were measured in liver tissue extracts using the Glutathione Assay Kit purchased from Cayman Chemicals (Montigny-le-Bretonneux, France). Hepatic carbonylated proteins were also assessed as valuable markers of oxidative stress [28]. Protein carbonyl quantification was carried out using the Protein Carbonyl Elisa Kit purchased from Enzo Life Sciences (Villeurbanne, France). Lipid peroxidation was assessed using the Lipid Peroxidation (MDA) Colorimetric/Fluorometric Assay Kit (K739) from BioVision. Protein expression of hepatic cytochrome P450 2E1 (CYP2E1) and heat shock cognate 70 (HSC70) (used as loading control) was assessed by western blot analysis as previously described [15], using respectively the antibodies from Oxford Biomedical Research (Oxford, MI) and Santa Cruz Biotechnology (Dallas, TX). The dilution used for the antibodies was 1:1000 for CYP2E1 and 1:500 for HSC70.

\section{RNA extraction and transcriptomic analysis}

For our transcriptomic analysis, 5 HFD mice and 5 ethanol-treated HFD mice were randomly chosen in each group of mice. Total RNA was extracted from 10-15 mg of mouse liver with the RNeasy Mini Kit (Qiagen, Courtaboeuf, France). Genome-wide expression profiling was then 
162

163

performed using the low-input QuickAmp labeling kit and SurePrint G3 Mouse GE v2 8x60K microarrays purchased from Agilent Technologies (Santa Clara, CA), as previously described [29]. Further information on transcriptomic analysis and gene set enrichment analysis (GSEA) is provided in the Supplementary methods 3.

\section{Hepatic lipid extraction and fatty acid analysis}

For hepatic fatty acid analysis, all HFD and ethanol-treated HFD mice ( $n=10$ per group) were investigated. Hepatic lipid extraction and fatty acid analysis were performed as previously described [30-32]. Further information regarding the experimental procedures is provided in the Supplementary methods 4 .

\section{Statistical analysis}

All results are expressed as mean \pm SEM (standard error of mean). Comparisons between groups were performed using one-way analysis of variance (ANOVA) with a post-hoc Newman-Keuls test, two-way ANOVA with a post-hoc Bonferroni test, Student $t$-test or nonparametric Mann-Whitney U test, as appropriate. All statistical analyses and graphics were performed using GraphPad Prism5 software (GraphPad Software, San Diego, CA, USA). 


\section{Results}

\section{Body weight, food consumption and energy intake}

As expected, mice fed the HFD (henceforth referred to as HFD mice) gained more body weight compared with mice fed the SD (SD mice) and the body weight gain was significant from the second week of HFD (Figure 1a). However, HFD mice consuming ethanol gained significantly less body weight during the last month compared with naive HFD mice (Figure 1a). This difference was apparently not related to lower food consumption in ethanol-treated obese mice in this period of time (Figure 1b). HFD induced a transient increase in food consumption (Figure 1b), as already observed in different rodent models of diet-induced obesity (DIO) [33, 34]. Caloric intake was lower in SD mice compared with HFD mice and within the latter group, ethanol-treated HFD mice consumed overall more energy than HFD mice (Figure 1c), due to the calories provided by ethanol (7 kcal/g).

\section{Serum parameters and liver weight}

Different serum parameters were serially measured during the 4-month experiment (Figure 2a). Serum ethanol concentrations in ethanol-treated HFD mice were comprised between 0.5 and $0.7 \mathrm{~g} / \mathrm{l}$ (ca. 11 and $15 \mathrm{mM}$ ) throughout the experiment. However, it should be underlined that ethanol concentrations were measured in the morning after an overnight fast. Hence, it cannot be excluded that these concentrations might have been higher if measured in the fed state and during the dark cycle when the highest ethanol consumption usually occurs in mice [35, 36]. Serum glucose levels were increased in naive and ethanol-treated HFD mice during the course of the experiment although hyperglycemia was reduced in ethanol-treated HFD mice after 3 months but not afterwards. Serum total cholesterol was increased in naive and ethanol-treated HFD mice throughout the experiment 
but hypercholesterolemia was lower in ethanol-treated HFD mice after 4 months. Serum triglyceride levels were enhanced in ethanol-treated HFD mice during the first 3 months but returned to normal levels after 4 months. Although serum levels of triglycerides were enhanced in ethanol-treated HFD mice compared with HFD mice at months 2 and 3, it seemed unlikely that this unfavorable metabolic profile might be due to the higher energy intake brought only by ethanol during the overnight fast. Indeed, this higher caloric intake would also have induced higher serum triglycerides at month 4 but also unfavorable profiles on serum glucose and total cholesterol throughout the experiment. Serum ALT activity was higher in naive and ethanol-treated HFD mice during the experiment but a significant reduction of this activity was observed in ethanol-treated HFD mice after 3 and 4 months. At these periods of time, AST activity was significantly increased in naive HFD mice, but not in ethanol-treated HFD mice, compared with SD mice. There was no modification of the serum total antioxidant capacity whatever the groups of mice and the timing of measurement (Supplementary figure 2). At the end of the 4-month experiment, serum insulin levels and liver weight were enhanced in HFD mice compared with the SD mice (Figure 2b and 2c). However, there was no difference between naive and ethanol-treated HFD mice (Figure 2b and 2c). Interestingly, a trend $(\mathrm{p}=0.055)$ toward higher serum adiponectin levels was found in HFD mice treated with ethanol compared to the other groups of mice (Figure $2 b$ ).

\section{Liver steatosis, necroinflammation and apoptosis}

A thorough evaluation of steatosis, necroinflammation, apoptosis and fibrosis was performed at the end of the experiment in 9 SD mice, 10 naive HFD mice and 10 ethanol-treated HFD mice. As expected, steatosis was present in a vast majority of hepatocytes in DIO mice (Figure 3a). However, the percentage of hepatocytes with steatosis was slightly but significantly reduced in ethanol-treated HFD mice (87\%) compared with naive HFD mice (94\%) (Figure 3a). More strikingly, the pattern of steatosis was modified in ethanol-treated HFD mice, which presented significantly less 
microvesicular steatosis compared to naive HFD mice (Figure 3b and 3c). Indeed, the percentage of steatotic hepatocytes presenting microvesicular steatosis was respectively 49 and 23\% in naive and ethanol-treated HFD mice (Figure 3b). On the other hand, ethanol-treated HFD mice presented significantly more mediovesicular and macrovacuolar steatosis compared to naive HFD mice (Figure 3b and 3c). Regarding necroinflammation, there was however no difference between naive and ethanol-treated HFD mice. Indeed, in each group, there were 9 mice scored 1 and 1 mouse scored 2 for this liver lesion. The inflammatory infiltrates, which were observed in the portal tracts and the lobules, consisted mainly of lymphocytes and Kupffer cells, with few neutrophils. In contrast, ethanol drinking reduced the apoptosis score. Indeed, there were 4 naive HFD mice presenting apoptotic bodies in the hepatic parenchyma (score 1), whereas this pathological feature was not observed in ethanol-treated HFD mice. In keeping with these results, our microarray data showed a significant $(\mathrm{p}<0.05)$ downregulation of different genes involved in apoptosis in ethanoltreated HFD mice compared with naive HFD mice. This was for instance the case for Card11 (43\%), Bcl2l14 (-36\%), Aen (-26\%), Tnfsf12 (-23\%), Acin1 (-22\%) and Bid (-11\%). In contrast, there was a significant upregulation of some anti-apoptotic genes such as Faim2 (+35\%), Aven (+19\%), Tmbim4 (+13\%) and Dad1 (+11\%). However, GSEA did not reveal an overall change in the expression of genes involved in cell death.

\section{Assessment of liver fibrosis by histology and SHG microscopy}

Portal and perisinusoidal fibrosis was either absent (score 0) or mild (score 1) in all DIO mice (data not shown). Whereas the mean score of perisinusoidal fibrosis was similar between naive and ethanol-treated HFD mice, that of portal fibrosis tended to be lower in the last group (Figure 4a). In order to have a quantitative assessment of fibrosis, liver fibrillar collagen deposition was assessed by using SHG microscopy and the percentage of liver area with fibrosis was calculated for each mouse, as previously reported [24, 25]. A trend towards reduced area of fibrosis was observed in 
ethanol-treated HFD mice compared to naive HFD mice (Figure 4b and 4c) but the difference did not reach statistical difference $(\mathrm{p}=0.10)$.

\section{Investigations on liver lipids and fatty acids}

Liver fatty acid analysis was subsequently carried out in order to better understand the altered pattern of fatty liver in ethanol-treated HFD mice. Whereas the mass of fatty acids from total lipids was similar between ethanol-treated HFD mice and naive HFD mice, more fatty acids were found in triglycerides and phospholipids (Figure 5a). The 5 most abundant hepatic fatty acids in HFD mice were, by decreasing order of magnitude, oleic acid (C18:1 n-9; 44.1\%), palmitic acid (C16:0; 27.1\%), cis-vaccenic acid (C18:1 n-7; 6.7\%), palmitoleic acid (C16:1 n-7; 6.0\%) and linoleic acid (C18:2 n-6; 4.8\%) (Figure 5b and data not shown). The proportion of the remaining fatty acids was near or below $2 \%$ (data not shown). There was a significant decrease in the proportion of palmitic acid and an increase in that of oleic acid in ethanol-treated HFD mice compared with naive HFD mice (Figure 5b). Overall, the proportion of SFAs was significantly reduced in ethanol-treated HFD mice whereas that of monounsaturated fatty acids (MUFAs) was enhanced (Figure 5b). Moreover, the $\Delta$ 9-desaturation index, calculated as the ratio $(\mathrm{C} 16: 1 \mathrm{n}-7+\mathrm{C} 18: 1 \mathrm{n}-9) /(\mathrm{C} 16: 0+\mathrm{C} 18: 0)$, was significantly enhanced in ethanol-treated HFD mice compared with naive HFD mice (Figure 5c), suggesting higher hepatic stearoyl-CoA desaturase (SCD1) activity by ethanol intake. However, Scd1 mRNA expression was not increased in ethanol-treated HFD mice (data not shown). Interestingly, our genome-wide expression profiling showed in ethanol-treated HFD mice an upregulation of genes encoding 4 enzymes involved in glycolysis and conversion of pyruvate to acetyl-coenzyme A (Gpi1, Aldob, Pklr, Pdhb), 4 enzymes implicated in fatty acid synthesis and elongation (Acly, Acaca, Me1, Elovl6) and one enzyme participating in triglyceride formation (Lpin1) (Figure 5d). In addition, we found an increased mRNA expression of thyroid hormone 
responsive protein (Thrsp, also referred to as Spot14), cell death-inducing DFFA-like effector a (Cidea) and adipogenin (Adig), three proteins involved in lipid synthesis and storage (Figure 5d).

\section{Microarray analysis, GSEA and MRC complex activity}

Our microarray analysis complemented by GSEA revealed in naive HFD mice a significant enrichment of the GO gene sets corresponding to "collagen fibril organization" and "extracellular structure organization”, in comparison with ethanol-treated HFD mice (Figure 6a). Accordingly, a marked reduction of Col1a1, Col1a2, Col2a1 and Col3a1 mRNA levels was for instance observed in these mice (Figure 6a). GSEA also disclosed in naive HFD mice a significant enrichment of the GO gene sets related to "cell chemotaxis" and "leukocyte chemotaxis", in comparison with ethanoltreated HFD mice with reduced $C x 3 c 11, C x c 11, C c r 2$ and $C x 3 c r 1$ mRNA expression in the latter group of mice (Figure 6b). In contrast, GSEA showed in ethanol-treated HFD a significant enrichment of the GO gene sets corresponding to "oxidative phosphorylation” (OXPHOS) and “MRC complex assembly”, compared with naive HFD mice (Figure 7a). For example, increased mRNA levels of Nd1, Nd3, Nd5, Cox5a, Cox7a2, Atp5d, Atp8 and Ndufs4 were observed in ethanol-treated HFD mice (Figure 7a). Regarding MRC complexes activity, no difference was found between the groups for complex I activity, whereas HFD-induced reduction of complex II activity was significantly restored in ethanol-treated HFD mice (Figure 7b).

\section{Investigations on oxidative stress and proteasome gene expression}

Investigations were also carried out on oxidative stress and cellular defense systems in liver. Whereas there was no difference between the groups for total liver GSH, the GSSG/GSH ratio was significantly decreased in ethanol-treated HFD mice compared with SD mice (Figure 8a). Liver carbonylated proteins were enhanced in DIO mice compared with SD mice but there was no 
301

302

303

304

305

difference between naive and ethanol-treated HFD mice (Figure 8a). Hepatic levels of malondialdehyde (MDA), reflecting lipid peroxidation, tended to be higher in HFD mice compared to SD mice but there was no statistical difference between the different groups of animals. The protein expression of CYP2E1 was slightly (18\%) but significantly reduced in ethanol-treated HFD mice compared with naive HFD mice (Figure 8b), while cyp2e1 mRNA expression was not different between these groups $(1.00 \pm 0.06$ and $0.98 \pm 0.07$ in naive HFD mice and ethanol-treated HFD mice, respectively). Our microarray analysis complemented by GSEA also revealed in naive HFD mice a moderate but significant enrichment $(\mathrm{p}=0.016)$ of the GO gene set corresponding to “response to oxidative stress” in comparison with ethanol-treated HFD mice (Supplementary figure 3a). A reduction of $G p x 3, G p x 7, G p x 8, H m o x 1$, Ogg1 and Sod3 mRNA expression was for example observed in the latter group of mice (Supplementary figure 3b). Finally, GSEA showed in ethanoltreated HFD a significant enrichment of the GO gene set corresponding to the "proteasome complex”, compared with naive HFD mice (Figure 8c). For instance, increased mRNA levels of Psmb4, Psmb7, Psmc1, Psmc4, Psmd9 and Psmd13 were observed in ethanol-treated HFD mice (Figure 8c). 
Light-to-moderate chronic ethanol consumption could have beneficial effects on NAFLD in patients $319[7,8,10-12]$, although some studies did not confirm these effects [12-14]. In this study, we used a mouse model of DIO in an attempt to better understand how moderate alcohol consumption could be beneficial on NAFLD. Thanks to different biochemical, analytical and transcriptomic analyses performed in mouse liver, our investigations suggested that moderate chronic ethanol consumption may alleviate NAFLD by several mechanisms including the generation of non-toxic lipid species such as triglycerides enriched in MUFAs, reduced expression of profibrotic and proinflammatory genes and restauration of mitochondrial function.

\section{Murine models of NAFLD and moderate ethanol consumption}

Our DIO model fulfilled the different recommended items required for a relevant mouse model of $\mathrm{NASH}$, in particular regarding overweight, hyperinsulinemia, hyperglycemia and raised serum transaminase activity [37]. However, it is noteworthy that our naive HFD mice presented borderline NASH rather than definite NASH, as discussed afterwards.

Regarding ethanol exposure (ca. $10 \mathrm{~g} / \mathrm{kg} /$ day corresponding to $15.9 \%$ of calories from alcohol), it might be considered as high when compared to humans. However, previous investigations indicated that our protocol of alcohol administration can be considered as a bona fide model of moderate chronic ethanol consumption. First, although data are scarce, it has been shown that mice metabolize ethanol at a greater rate than do rats and humans [38]. Second, serum ethanol concentrations in ethanol-treated HFD mice were between 0.5 and $0.7 \mathrm{~g} / \mathrm{l}$, which are below the toxic range in humans (starting from 0.8-1 g/l) [39, 40]. Third, exposure of the livers to high ethanol concentrations would have led to increased CYP2E1 expression at the mRNA and protein levels 
[41-43], which was not observed in ethanol-treated HFD mice. Finally, ethanol exposure in our murine model was similar (or even lower) to previous studies in rodents investigating the effects of moderate alcohol consumption on different tissues and parameters [19, 44-46].

A caveat of our investigations was that ethanol-treated HFD mice ingested ethanol before blood and liver collection since these animals were allowed to drink during the different episodes of overnight fast scheduled in the study. Thus, some results observed in ethanol-treated HFD mice might have been directly induced by the presence of ethanol (and possibly the corresponding calories) during the few hours preceding the biological sample collection, in addition to the longterm effects of the moderate consumption of ethanol.

\section{Moderate chronic ethanol consumption alleviates NAFLD in obese mice}

Moderate chronic ethanol consumption in HFD mice significantly decreased serum ALT and AST activity, thus indicating NAFLD alleviation, although the mean necroinflammation score was similar between ethanol-treated and naive HFD mice. However, no apoptotic bodies was observed in ethanol-treated HFD mice, in contrast to naive HFD mice. Because hepatic apoptosis can be associated with increased serum transaminase activity $[47,48]$, our data suggested that lower serum ALT and AST activity in ethanol-treated HFD mice could be linked to reduced hepatic apoptosis. In keeping with this hypothesis, these mice presented a downregulation of several genes involved in apoptosis and an upregulation of some anti-apoptotic genes. Finally, ethanol consumption tended to reduce hepatic fibrosis, in particular in portal areas. Interestingly, a recent study in a rat model of NAFLD reported that a moderate chronic ethanol consumption improved liver fibrosis and decreased the mRNA expression of several profibrotic genes such as TGF- $\beta$, $\alpha$-SMA and collagen [18]. 


\section{NAFLD alleviation is associated with increased serum adiponectin and higher hepatic levels of} triglycerides and MUFAs

The mechanism(s) whereby light-to-moderate alcohol consumption could be beneficial on NAFLD is poorly understood, possibly because only a few experimental investigations have tackled this issue [15-17]. Some clinical and experimental investigations suggested a role of insulin resistance improvement, possibly via enhanced circulating adiponectin levels [15, 49]. Interestingly, adiponectin is able not only to alleviate fatty liver but also hepatic necroinflammation and fibrosis $[50,51]$. In this study, serum adiponectin levels tended to be higher in ethanol-treated HFD mice compared to naive HFD mice but this was not associated with lower serum insulin concentrations.

Our fatty acid analysis revealed that moderate chronic ethanol consumption significantly increased the amount of both hepatic triglycerides and phospholipids (as measured by their fatty acid amounts), consistent with larger lipid droplets. This was accompanied with a significant decrease in the proportion of palmitic acid and an increase in that of oleic acid in ethanol-treated HFD mice compared with naive HFD mice as well as a greater $\Delta 9$-desaturation index, suggesting higher SCD1 activity. Thus, ethanol-induced NAFLD improvement might be related to the lower hepatic levels of palmitic acid and higher levels of triglycerides since these lipid species are respectively harmful and beneficial for the hepatocytes, as discussed afterwards. Interestingly, higher SCD1 activity in ethanol-treated HFD mice might also have explained the significant increase in serum triglyceride levels in these mice. Indeed, high SCD1 activity favors triglyceride secretion from hepatocytes [52, 53]. However, further investigations will be required in order to explain why hypertriglyceridemia was transient in ethanol-treated HFD mice and no longer observed after 4 months. Nonetheless, reduced body weight and possibly fat mass might have played a role. 
Numerous investigations previously reported that excess of palmitic acid is deleterious for the liver, in particular by inducing hepatocyte oxidative stress, endoplasmic reticulum (ER) stress and eventually apoptosis [54-56]. Moreover, lipotoxicity-induced mitochondrial dysfunction could play a major role in the pathogenesis of NASH [55-58]. By inducing cell death and favoring the release of extracellular vesicles, palmitic acid could also play a key role in the pathogenesis of NASH by promoting inflammation and fibrosis $[55,56,59]$. It is noteworthy that a lipidomic analysis in NAFLD patients showed a trend toward higher hepatic levels of palmitic acid and lower levels of oleic acid in NASH compared with simple fatty liver [60]. On the other hand, increased conversion of palmitate to MUFAs via higher SCD1 activity favors accretion of neutral lipids (triglycerides or cholesterol ester) and protects against palmitate-induced cell death [61-63]. Interestingly, SCD1 knockout mice fed a methionine-choline deficient (MCD) diet had less steatosis but increased hepatocellular apoptosis, liver injury, and fibrosis compared with wild-type mice [64]. Similarly, diacylglycerol acyltransferase 2 (DGAT2) antisense oligonucleotide treatment in MCD diet-fed mice decreased steatosis but enhanced hepatic free fatty acids, oxidative stress, lobular necroinflammation and fibrosis [65]. Hence, these investigations and others [54-56] support a protective role of triglyceride accumulation against SFA-induced lipotoxicity.

NAFLD alleviation is associated with larger lipid droplets and less microvesicular steatosis suggesting restauration of mitochondrial function

NAFLD alleviation in ethanol-treated HFD mice was associated with larger lipid droplets. Lipid droplet growth is deemed to be due to the relocalization of several triglyceride synthesis enzymes (e.g. GPAT4, AGPAT3, DGAT2) from the ER to lipid droplets [66, 67]. Further investigations will be needed in order to determine whether this mechanism occurred in ethanol-treated HFD mice. Nevertheless, these mice presented higher expression of several enzymes involved in lipogenesis such as ATP citrate lyase (Acly), acetyl-CoA carboxylase 1 (Acaca), malic enzyme (Me1) and Lipin 
1 (Lpin1). Thus, besides enzyme relocalization, enhanced expression of lipogenic enzymes might have favored lipid droplet expansion in ethanol-treated HFD mice. In keeping with this assumption, our previous investigations in ob/ob mice showed that moderate chronic ethanol consumption led to an increase in the hepatic mRNA levels of Acaca, fatty acid synthase (Fas) and Scd1, which was associated with an enlargement of the lipid droplet size [15]. Lipid droplet growth is also dependent on the expression of the CIDE proteins, which promote the formation of large lipid droplets in different tissues including liver [68, 69]. Interestingly, Cidea mRNA expression was increased by 2.5-fold in ethanol-treated HFD mice compared with naive HFD mice.

Whatever its etiology, microvesicular steatosis is thought to be deleterious for the liver, in particular as the consequence of mitochondrial dysfunction and energy shortage [70-72]. Interestingly, a previous study in NAFLD patients showed that the presence of microvesicular steatosis was significantly associated with megamitochondria, ballooning cell injury, more advanced fibrosis and diagnosis of NASH [73]. In the present study, the occurrence of less microvesicular steatosis in ethanol-treated HFD mice might be linked to an improvement of mitochondrial function via transcriptional mechanisms. Indeed, GSEA revealed in these mice a significant enrichment of the expression of genes involved in OXPHOS and MRC complex assembly. Moreover, this transcriptional effect might have explained why MRC complex II activity was no longer decreased in ethanol-treated HFD mice compared with naive HFD mice. However, it cannot be excluded that restoration of mitochondrial function in ethanol-treated HFD mice might also be the mere consequence of reduced levels of SFAs including palmitic acid.

\section{Other potential mechanisms involved in NAFLD alleviation}

GSEA also disclosed that ethanol drinking lessened the hepatic expression of a wide range of genes involved in fibrosis and leucocyte chemotaxis. Although moderate chronic ethanol consumption might have directly lessened the expression of these genes, a reduction of apoptosis might have 
439

440

441

442

443

444

been indirectly involved. Indeed, hepatocyte apoptosis can favor both inflammation and fibrosis [74, 75]. Nevertheless, the downregulation of proinflammatory and profibrotic genes in ethanoltreated HFD mice was not associated with a significant improvement of the necroinflammation and fibrosis scores, although there was a trend toward less fibrosis in these mice. However, it is noteworthy that both necroinflammation and fibrosis was mild in our DIO mouse model, indicating borderline NASH. Hence, any improvement of these lesions might be difficult to appraise. Accordingly, more prolonged exposure to HFD and ethanol might have been needed in order to significantly alleviate these lesions.

Liver GSSG/GSH was reduced in ethanol-treated HFD mice compared to naive HFD mice, thus suggesting an alleviation of some components of oxidative stress such as reduced CYP2E1 protein expression. This assumption was also supported by a global reduction in ethanol-treated HFD mice of the mRNA expression of different genes involved in the response to oxidative stress. Nevertheless, ethanol consumption significantly enhanced the mRNA levels of several genes encoding proteasome subunits, which may reflect an adaptive response in order to get rid of some damaged proteins $[76,77]$. Since the proteasome plays a major role in cell protection, our results suggest that NAFLD alleviation by moderate chronic ethanol consumption might be, at least in part, linked to proteasome stimulation. Previous investigations reported that low ethanol exposure or moderate oxidative stress could activate the proteasome [78, 79]. In our study, however, ethanoltreated HFD mice presented evidence of lower oxidative stress and increased proteasome activity at the gene-expression level. Because the transcription factor nuclear factor erythroid 2-like 2 (NFE2L2, also referred to as Nrf2) is able to activate the expression of genes involved in both biological processes [76, 77], our data suggest a lack of robust Nrf2 activation in ethanol-treated HFD mice. Accordingly, a supervised GSEA with a dataset of 481 Nrf2 target genes (data set NFE2L2.V2) [80] did not reveal in these mice a significant enrichment of genes related to the Nrf2 pathway. Further investigations will be needed in order to determine why oxidative stress and proteasome activity seemed to be disconnected in ethanol-treated HFD mice. Nevertheless, our 
465

466

467

468

469

470

471

472

473

474

\section{Conclusion}

476 Our study performed in DIO mice suggests that moderate chronic ethanol consumption may 477 alleviate NAFLD progression, in particular as regards hepatic cytolysis and fibrosis. Several 478 mechanisms could be involved including a reduction in the levels of deleterious SFAs (including 479 palmitic acid) and a concomitant generation of non-toxic lipid species such as MUFAs. NAFLD 480 alleviation in ethanol-treated HFD mice was associated with larger lipid droplets and less 481 microvesicular steatosis, in keeping with a possible improvement of mitochondria function. 482 Genome-wide expression profiling and GSEA revealed an overall upregulation of genes involved in 483 the proteasome complex, thus suggesting possible stimulation of proteasome activity. Because there 484 was also evidence of lower oxidative stress in ethanol-treated HFD mice, further investigations will 485 be required in order to determine why moderate chronic ethanol intake could induce an opposite 486

previous investigations in ob/ob mice showed that fatty liver improvement induced by moderate ethanol consumption over 6 months was associated with some signs of mild oxidative stress such as reduced aconitase activity and higher MnSOD protein expression [15]. Hence, additional investigations will be required to determine whether further prolongation of the moderate alcohol drinking protocol might lead to stronger hepatic oxidative stress and loss of the beneficial effects on liver afforded by ethanol. Moreover, it should be underlined that hepatic fat accumulation can favor in the long term the occurrence of unfavorable extra-hepatic effects such as dyslipidemia (including hypertriglyceridemia and hypercholesterolemia), systemic inflammation and cardiovascular diseases [81, 82]. 
488 This work was supported by a grant from the Agence Nationale de la Recherche (ANR STEATOX 489 project ANR-13-CESA-0009). Simon Bucher was a recipient of a joint fellowship from the Région 490 Bretagne (ARED) and ANR. We are grateful to Alain Fautrel and Marine Seffals (histopathology 491 platform H2P2), Laurence Bernard-Touami (animal care facility ARCHE), Stéphanie Dutertre 492 (microscopy Rennes imaging center platform MRIC), all from the SFR Biosit UMS CNRS 3480 493 INSERM 018 SFR, for their excellent technical support. We also wish to thank Nicolas Collet 494 (Laboratoire de Biochimie-Toxicologie, CHU de Rennes) for his skilled technical assistance for the 495 serum analyses. We are grateful to INSERM (Institut National de la Recherche et de la Santé 496 Médicale) for its constant financial support.

\section{Conflict of interest statement}

499 On behalf of all authors, the corresponding author states that there is no conflict of interest. 


\section{References}

501 1. Rehm J (2011) The risks associated with alcohol use and alcoholism. Alcohol Res Health 34:135-143

502

503

504

505

506

507

508

509

510

511

512

513

514

515

516

517

518

519

520

521

2. Seitz HK, Bataller R, Cortez-Pinto H, et al (2018) Publisher Correction: Alcoholic liver disease. Nat Rev Dis Primers 4:18. http://doi.org/10.1038/s41572-018-0021-8

3. Louvet A, Mathurin P (2015) Alcoholic liver disease: mechanisms of injury and targeted treatment. Nat Rev Gastroenterol Hepatol 12:231-242. http://doi.org/10.1038/nrgastro.2015.35

4. GBD 2016 Alcohol Collaborators (2018) Alcohol use and burden for 195 countries and territories, 1990-2016: a systematic analysis for the Global Burden of Disease Study 2016. Lancet 392:1015-1035. http://doi.org/10.1016/S0140-6736(18)31310-2

5. Bonnet F, Disse E, Laville $\mathrm{M}$, et al (2012) Moderate alcohol consumption is associated with improved insulin sensitivity, reduced basal insulin secretion rate and lower fasting glucagon concentration in healthy women. Diabetologia 55:3228-3237. http://doi.org/10.1007/s00125-012-2701-3

6. Poli A, Marangoni F, Avogaro A, et al (2013) Moderate alcohol use and health: a consensus document. Nutr Metab Cardiovasc Dis 23:487-504. http://doi.org/10.1016/i.numecd.2013.02.007

7. Ajmera VH, Terrault NA, Harrison SA (2017) Is moderate alcohol use in nonalcoholic fatty liver disease good or bad? A critical review. Hepatology 65:2090-2099. http://doi.org/10.1002/hep.29055

8. Dunn W, Sanyal AJ, Brunt EM, et al (2012) Modest alcohol consumption is associated with decreased prevalence of steatohepatitis in patients with non-alcoholic fatty liver disease (NAFLD). J Hepatol 57:384-391. http://doi.org/10.1016/j.jhep.2012.03.024

9. Kwon HK, Greenson JK, Conjeevaram HS (2014) Effect of lifetime alcohol consumption on the histological severity of non-alcoholic fatty liver disease. Liver Int 34:129-135.

http://doi.org/10.1111/liv.12230

10. Moriya A, Iwasaki Y, Ohguchi S, et al (2015) Roles of alcohol consumption in fatty liver: a longitudinal study. J Hepatol 62:921-927. http://doi.org/10.1016/i.jhep.2014.11.025

11. Seitz HK, Mueller S, Hellerbrand C, Liangpunsakul S (2015) Effect of chronic alcohol consumption on the development and progression of non-alcoholic fatty liver disease (NAFLD). Hepatobiliary Surg Nutr 4:147-151. http://doi.org/10.3978/j.issn.2304-3881.2014.12.01

12. Kwon I, Jun DW, Moon J-H (2018) Effects of Moderate Alcohol Drinking in Patients with Nonalcoholic Fatty Liver Disease. Gut Liver. http://doi.org/10.5009/gnl18175

13. Ajmera V, Belt P, Wilson LA, et al (2018) Among Patients With Nonalcoholic Fatty Liver Disease, Modest Alcohol Use Is Associated With Less Improvement in Histologic Steatosis and Steatohepatitis. Clin Gastroenterol Hepatol 16:1511-1520.e5. http://doi.org/10.1016/i.cgh.2018.01.026

14. Sookoian S, Flichman D, Castaño GO, Pirola CJ (2016) Mendelian randomisation suggests no beneficial effect of moderate alcohol consumption on the severity of nonalcoholic fatty liver disease. Aliment Pharmacol Ther 44:1224-1234. http://doi.org/10.1111/apt.13828

15. Fromenty B, Vadrot N, Massart J, et al (2009) Chronic ethanol consumption lessens the gain of body weight, liver triglycerides, and diabetes in obese ob/ob mice. J Pharmacol Exp Ther 331:23-34. http://doi.org/10.1124/jpet.109.155168 
16. Kanuri G, Landmann M, Priebs J, et al (2016) Moderate alcohol consumption diminishes the development of non-alcoholic fatty liver disease (NAFLD) in ob/ob mice. Eur J Nutr 55:1153-1164. http://doi.org/10.1007/s00394-015-0929-7

17. Osaki A, Okazaki Y, Kimoto A, et al (2014) Beneficial effect of a low dose of ethanol on liver function and serum urate in rats fed a high-fat diet. J Nutr Sci Vitaminol 60:408-412. http://doi.org/10.3177/jnsv.60.408

18. Sun F, Zhuang Z, Zhang D, et al (2018) Chronic moderate alcohol consumption relieves high-fat highcholesterol diet-induced liver fibrosis in a rat model. Clin Exp Pharmacol Physiol 45:1046-1055. http://doi.org/10.1111/1440-1681.12976

19. Godfrey J, Jeanguenin L, Castro N, et al (2015) Chronic Voluntary Ethanol Consumption Induces Favorable Ceramide Profiles in Selectively Bred Alcohol-Preferring (P) Rats. PLoS ONE 10:e0139012. http://doi.org/10.1371/journal.pone.0139012

20. Klarich DS, Penprase J, Cintora P, et al (2017) Effects of moderate alcohol consumption on gene expression related to colonic inflammation and antioxidant enzymes in rats. Alcohol 61:25-31. http://doi.org/10.1016/i.alcohol.2017.02.179

21. Justice M, Ferrugia A, Beidler J, et al (2019) Effects of Moderate Ethanol Consumption on Lipid Metabolism and Inflammation Through Regulation of Gene Expression in Rats. Alcohol Alcohol 54:512. http://doi.org/10.1093/alcalc/agy079

22. Buron N, Porceddu M, Roussel C, et al (2017) Chronic and low exposure to a pharmaceutical cocktail induces mitochondrial dysfunction in liver and hyperglycemia: Differential responses between lean and obese mice. Environ Toxicol 32:1375-1389. http://doi.org/10.1002/tox.22331

23. Trak-Smayra V, Paradis V, Massart J, et al (2011) Pathology of the liver in obese and diabetic ob/ob and db/db mice fed a standard or high-calorie diet. Int J Exp Pathol 92:413-421.

http://doi.org/10.1111/j.1365-2613.2011.00793.x

24. Gailhouste L, Le Grand Y, Odin C, et al (2010) Fibrillar collagen scoring by second harmonic microscopy: a new tool in the assessment of liver fibrosis. J Hepatol 52:398-406. http://doi.org/10.1016/j.jhep.2009.12.009

25. Tabet E, Genet V, Tiaho F, et al (2016) Chlordecone potentiates hepatic fibrosis in chronic liver injury induced by carbon tetrachloride in mice. Toxicol Lett 255:1-10. http://doi.org/10.1016/j.toxlet.2016.02.005

26. Bucher S, Le Guillou D, Allard J, et al (2018) Possible Involvement of Mitochondrial Dysfunction and Oxidative Stress in a Cellular Model of NAFLD Progression Induced by Benzo[a]pyrene/Ethanol CoExposure. Oxid Med Cell Longev 2018:4396403. http://doi.org/10.1155/2018/4396403

27. Le Guillou D, Bucher S, Begriche K, et al (2018) Drug-Induced Alterations of Mitochondrial DNA Homeostasis in Steatotic and Nonsteatotic HepaRG Cells. J Pharmacol Exp Ther 365:711-726. http://doi.org/10.1124/jpet.117.246751

28. Baraibar MA, Ladouce R, Friguet B (2013) Proteomic quantification and identification of carbonylated proteins upon oxidative stress and during cellular aging. J Proteomics 92:63-70. http://doi.org/10.1016/j.jprot.2013.05.008

29. Bucher S, Tête A, Podechard N, et al (2018) Co-exposure to benzo[a]pyrene and ethanol induces a pathological progression of liver steatosis in vitro and in vivo. Scientific Reports 8:5963. http://doi.org/10.1038/s41598-018-24403-1 
30. Rioux V, Catheline $D$, Bouriel $M$, Legrand $P(2005)$ Dietary myristic acid at physiologically relevant levels increases the tissue content of C20:5 n-3 and C20:3 n-6 in the rat. Reprod Nutr Dev 45:599-612. http://doi.org/10.1051/rnd:2005048

31. Rioux V, Lemarchal $P$, Legrand $P$ (2000) Myristic acid, unlike palmitic acid, is rapidly metabolized in cultured rat hepatocytes. J Nutr Biochem 11:198-207. http://doi.org/10.1016/S0955-2863(00)00065$\underline{6}$

32. Rioux V, Pédrono F, Blanchard $\mathrm{H}$, et al (2013) Trans-vaccenate is $\Delta 13$-desaturated by FADS3 in rodents. J Lipid Res 54:3438-3452. http://doi.org/10.1194/jlr.M042572

33. Ravinet Trillou C, Delgorge C, Menet C, et al (2004) CB1 cannabinoid receptor knockout in mice leads to leanness, resistance to diet-induced obesity and enhanced leptin sensitivity. Int J Obes Relat Metab Disord 28:640-648. http://doi.org/10.1038/sj.ijo.0802583

34. Guerville M, Leroy A, Sinquin A, et al (2017) Western-diet consumption induces alteration of barrier function mechanisms in the ileum that correlates with metabolic endotoxemia in rats. Am J Physiol Endocrinol Metab 313:E107-E120. http://doi.org/10.1152/ajpendo.00372.2016

35. Goldstein DB, Kakihana R (1977) Circadian rhythms of ethanol consumption by mice: a simple computer analysis for chronopharmacology. Psychopharmacology (Berl) 52:41-45.

http://dx.doi.org/10.1007/BF00426598

36. Jelic $P$, Shih MF, Taberner PV (1998) Diurnal variation in plasma ethanol levels of TO and CBA mice on chronic ethanol drinking or ethanol liquid diet schedules. Psychopharmacology (Berl) 138:143-150. http://doi.org/10.1007/s002130050656

37. Haczeyni F, Yeh MM, loannou GN, et al (2018) Mouse models of non-alcoholic steatohepatitis: A reflection on recent literature. J Gastroenterol Hepatol 33:1312-1320.

http://doi.org/10.1111/igh.14122

38. Livy DJ, Parnell SE, West JR (2003) Blood ethanol concentration profiles: a comparison between rats and mice. Alcohol 29:165-171. http://doi.org/10.1016/S0741-8329(03)00025-9

39. Stead AH, Moffat AC (1983) A collection of therapeutic, toxic and fatal blood drug concentrations in man. Hum Toxicol 2:437-464. http://doi.org/10.1177/096032718300200301

40. Schulz M, Iwersen-Bergmann S, Andresen H, Schmoldt A (2012) Therapeutic and toxic blood concentrations of nearly 1,000 drugs and other xenobiotics. Crit Care 16:R136. http://doi.org/10.1186/cc11441

41. Ronis MJ, Huang J, Crouch J, et al (1993) Cytochrome P450 CYP 2E1 induction during chronic alcohol exposure occurs by a two-step mechanism associated with blood alcohol concentrations in rats. J Pharmacol Exp Ther 264:944-950

42. Badger TM, Huang J, Ronis M, Lumpkin CK (1993) Induction of cytochrome P450 2E1 during chronic ethanol exposure occurs via transcription of the CYP 2E1 gene when blood alcohol concentrations are high. Biochem Biophys Res Commun 190:780-785. http://doi.org/10.1006/bbrc.1993.1117

43. Roberts BJ, Song BJ, Soh Y, et al (1995) Ethanol induces CYP2E1 by protein stabilization. Role of ubiquitin conjugation in the rapid degradation of CYP2E1. J Biol Chem 270:29632-29635. http://doi.org/10.1074/ibc.270.50.29632 
44. Wang $Y$, Seitz HK, Wang X-D (2010) Moderate alcohol consumption aggravates high-fat diet induced steatohepatitis in rats. Alcohol Clin Exp Res 34:567-573. http://doi.org/10.1111/i.1530$\underline{0277.2009 .01122 . x}$

45. Sanchez Vega MC, Chong S, Burne THJ (2013) Early gestational exposure to moderate concentrations of ethanol alters adult behaviour in C57BL/6J mice. Behav Brain Res 252:326-333. http://doi.org/10.1016/j.bbr.2013.06.003

46. Stragier E, Martin V, Davenas E, et al (2015) Brain plasticity and cognitive functions after ethanol consumption in C57BL/6J mice. Transl Psychiatry 5:e696. http://doi.org/10.1038/tp.2015.183

47. Haouzi D, Lekehal $M$, Tinel $M$, et al (2001) Prolonged, but not acute, glutathione depletion promotes Fas-mediated mitochondrial permeability transition and apoptosis in mice. Hepatology 33:1181-1188. http://doi.org/10.1053/jhep.2001.24235

48. Lacronique $\mathrm{V}$, Mignon A, Fabre $\mathrm{M}$, et al (1996) Bcl-2 protects from lethal hepatic apoptosis induced by an anti-Fas antibody in mice. Nat Med 2:80-86. http://doi.org/10.1038/nm0196-80

49. Nova E, Baccan GC, Veses A, et al (2012) Potential health benefits of moderate alcohol consumption: current perspectives in research. Proc Nutr Soc 71:307-315. http://doi.org/10.1017/S0029665112000171

50. Fang H, Judd RL (2018) Adiponectin Regulation and Function. Compr Physiol 8:1031-1063. http://doi.org/10.1002/cphy.c170046

51. Polyzos SA, Kountouras J, Zavos C, Tsiaousi E (2010) The role of adiponectin in the pathogenesis and treatment of non-alcoholic fatty liver disease. Diabetes Obes Metab 12:365-383. http://doi.org/10.1111/j.1463-1326.2009.01176.x

52. Legrand $P$, Catheline D, Fichot MC, Lemarchal P (1997) Inhibiting delta9-desaturase activity impairs triacylglycerol secretion in cultured chicken hepatocytes. J Nutr 127:249-256. http://doi.org/10.1093/in/127.2.249

53. Attie AD, Krauss RM, Gray-Keller MP, et al (2002) Relationship between stearoyl-CoA desaturase activity and plasma triglycerides in human and mouse hypertriglyceridemia. J Lipid Res 43:1899-1907. http://doi.org/10.1194/jlr.M200189-JLR200

54. Cazanave SC, Gores GJ (2010) Mechanisms and clinical implications of hepatocyte lipoapoptosis. Clin Lipidol 5:71-85. http://doi.org/10.2217/clp.09.85

55. Hirsova P, Ibrahim SH, Gores GJ, Malhi H (2016) Lipotoxic lethal and sublethal stress signaling in hepatocytes: relevance to NASH pathogenesis. J Lipid Res 57:1758-1770. http://doi.org/10.1194/jilr.R066357

56. Marra F, Svegliati-Baroni G (2018) Lipotoxicity and the gut-liver axis in NASH pathogenesis. J Hepatol 68:280-295. http://doi.org/10.1016/i.jhep.2017.11.014

57. Begriche K, Massart J, Robin M-A, et al (2013) Mitochondrial adaptations and dysfunctions in nonalcoholic fatty liver disease. Hepatology 58:1497-1507. http://doi.org/10.1002/hep.26226

58. Simões ICM, Fontes A, Pinton $P$, et al (2018) Mitochondria in non-alcoholic fatty liver disease. Int J Biochem Cell Biol 95:93-99. http://doi.org/10.1016/i.biocel.2017.12.019 
59. Hirsova P, Ibrahim SH, Krishnan A, et al (2016) Lipid-Induced Signaling Causes Release of Inflammatory Extracellular Vesicles From Hepatocytes. Gastroenterology 150:956-967. http://doi.org/10.1053/i.gastro.2015.12.037

60. Puri P, Baillie RA, Wiest MM, et al (2007) A lipidomic analysis of nonalcoholic fatty liver disease. Hepatology 46:1081-1090. http://doi.org/10.1002/hep.21763

61. Listenberger LL, Han X, Lewis SE, et al (2003) Triglyceride accumulation protects against fatty acidinduced lipotoxicity. Proc Natl Acad Sci USA 100:3077-3082.

http://doi.org/10.1073/pnas.0630588100

62. Busch AK, Gurisik E, Cordery DV, et al (2005) Increased fatty acid desaturation and enhanced expression of stearoyl coenzyme A desaturase protects pancreatic beta-cells from lipoapoptosis. Diabetes 54:2917-2924. http://doi.org/10.2337/diabetes.54.10.2917

63. Alkhouri N, Dixon L, Feldstein AE (2009) Lipotoxicity in nonalcoholic fatty liver disease: not all lipids are created equal. Expert Rev Gastroenterol Hepatol 3:445-451. http://doi.org/10.1586/egh.09.32

64. Li ZZ, Berk M, McIntyre TM, Feldstein AE (2009) Hepatic lipid partitioning and liver damage in nonalcoholic fatty liver disease: role of stearoyl-CoA desaturase. J Biol Chem 284:5637-5644. http://doi.org/10.1074/jbc.M807616200

65. Yamaguchi K, Yang L, McCall S, et al (2007) Inhibiting triglyceride synthesis improves hepatic steatosis but exacerbates liver damage and fibrosis in obese mice with nonalcoholic steatohepatitis. Hepatology 45:1366-1374. http://doi.org/10.1002/hep.21655

66. Thiam AR, Farese RV, Walther TC (2013) The biophysics and cell biology of lipid droplets. Nat Rev Mol Cell Biol 14:775-786. http://doi.org/10.1038/nrm3699

67. Wilfling $\mathrm{F}$, Wang $\mathrm{H}$, Haas JT, et al (2013) Triacylglycerol synthesis enzymes mediate lipid droplet growth by relocalizing from the ER to lipid droplets. Dev Cell 24:384-399. http://doi.org/10.1016/j.devcel.2013.01.013

68. Yang H, Galea A, Sytnyk V, Crossley M (2012) Controlling the size of lipid droplets: lipid and protein factors. Current Opinion in Cell Biology 24:509-516. http://doi.org/10.1016/j.ceb.2012.05.012

69. Gao G, Chen F-J, Zhou L, et al (2017) Control of lipid droplet fusion and growth by CIDE family proteins. Biochim Biophys Acta Mol Cell Biol Lipids 1862:1197-1204. http://doi.org/10.1016/i.bbalip.2017.06.009

70. Fromenty B, Pessayre D (1995) Inhibition of mitochondrial beta-oxidation as a mechanism of hepatotoxicity. Pharmacology \& Therapeutics 67:101-154. http://doi.org/10.1016/0163$\underline{7258(95) 00012-6}$

71. Begriche K, Massart J, Robin M-A, et al (2011) Drug-induced toxicity on mitochondria and lipid metabolism: mechanistic diversity and deleterious consequences for the liver. J Hepatol 54:773-794. http://doi.org/10.1016/j.jhep.2010.11.006

72. Hegarty R, Deheragoda M, Fitzpatrick E, Dhawan A (2018) Paediatric fatty liver disease (PeFLD): All is not NAFLD - Pathophysiological insights and approach to management. J Hepatol 68:1286-1299. http://doi.org/10.1016/j.jhep.2018.02.006

73. Tandra S, Yeh MM, Brunt EM, et al (2011) Presence and significance of microvesicular steatosis in nonalcoholic fatty liver disease. J Hepatol 55:654-659. http://doi.org/10.1016/i.jhep.2010.11.021 
74. Canbay A, Friedman S, Gores GJ (2004) Apoptosis: the nexus of liver injury and fibrosis. Hepatology 39:273-278. http://doi.org/10.1002/hep.20051

75. Zhan S-S, Jiang JX, Wu J, et al (2006) Phagocytosis of apoptotic bodies by hepatic stellate cells induces NADPH oxidase and is associated with liver fibrosis in vivo. Hepatology 43:435-443. http://doi.org/10.1002/hep.21093

76. Chapple SJ, Siow RCM, Mann GE (2012) Crosstalk between Nrf2 and the proteasome: therapeutic potential of Nrf2 inducers in vascular disease and aging. Int J Biochem Cell Biol 44:1315-1320. http://doi.org/10.1016/j.biocel.2012.04.021

77. Jung T, Höhn A, Grune T (2014) The proteasome and the degradation of oxidized proteins: Part II protein oxidation and proteasomal degradation. Redox Biol 2:99-104. http://doi.org/10.1016/i.redox.2013.12.008

78. Osna NA, Haorah J, Krutik VM, Donohue TM (2004) Peroxynitrite alters the catalytic activity of rodent liver proteasome in vitro and in vivo. Hepatology 40:574-582. http://doi.org/10.1002/hep.20352

79. Donohue TM, Thomes PG (2014) Ethanol-induced oxidant stress modulates hepatic autophagy and proteasome activity. Redox Biol 3:29-39. http://doi.org/10.1016/j.redox.2014.10.006

80. Malhotra D, Portales-Casamar E, Singh A, et al (2010) Global mapping of binding sites for Nrf2 identifies novel targets in cell survival response through ChIP-Seq profiling and network analysis. Nucleic Acids Res 38:5718-5734. http://doi.org/10.1093/nar/gkq212

81. Byrne CD, Targher G (2015) NAFLD: a multisystem disease. J Hepatol 62:S47-64. http://doi.org/10.1016/i.jhep.2014.12.012

82. Than NN, Newsome PN (2015) A concise review of non-alcoholic fatty liver disease. Atherosclerosis 239:192-202. http://doi.org/10.1016/j.atherosclerosis.2015.01.001 
a.

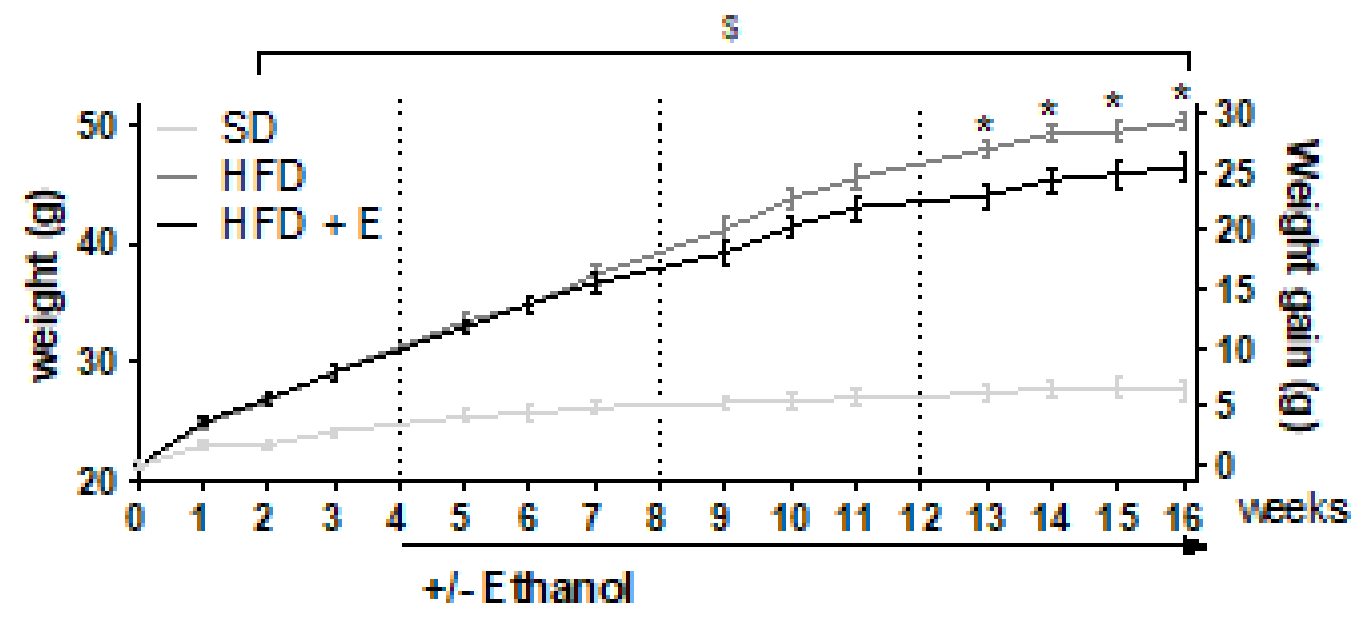

b.

Food consumption

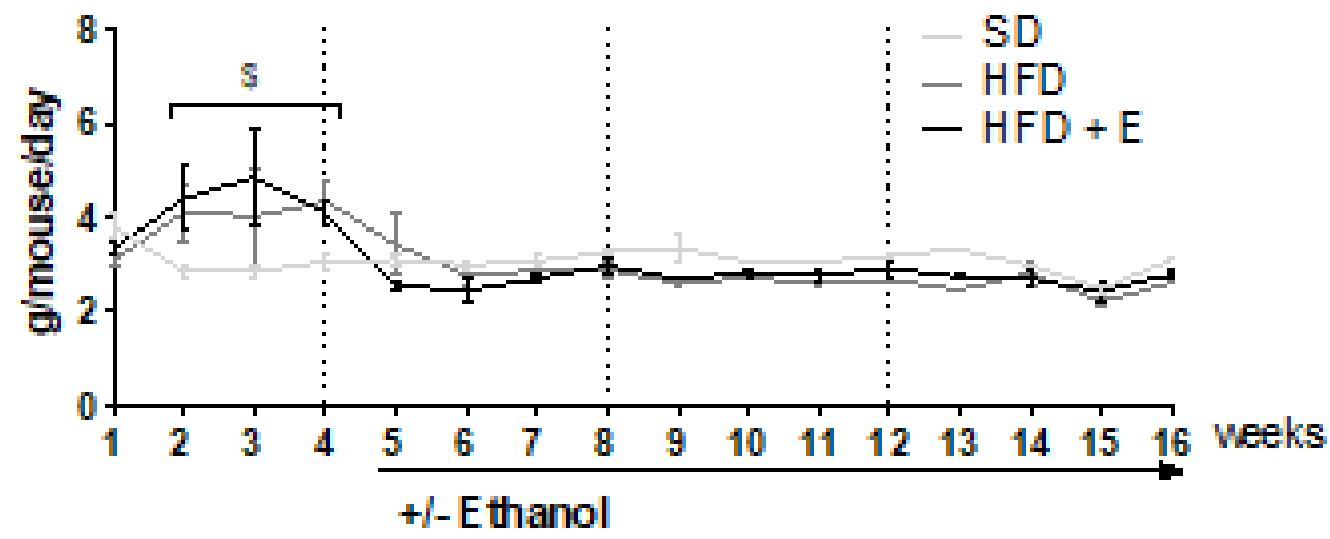

c.

Energy intake

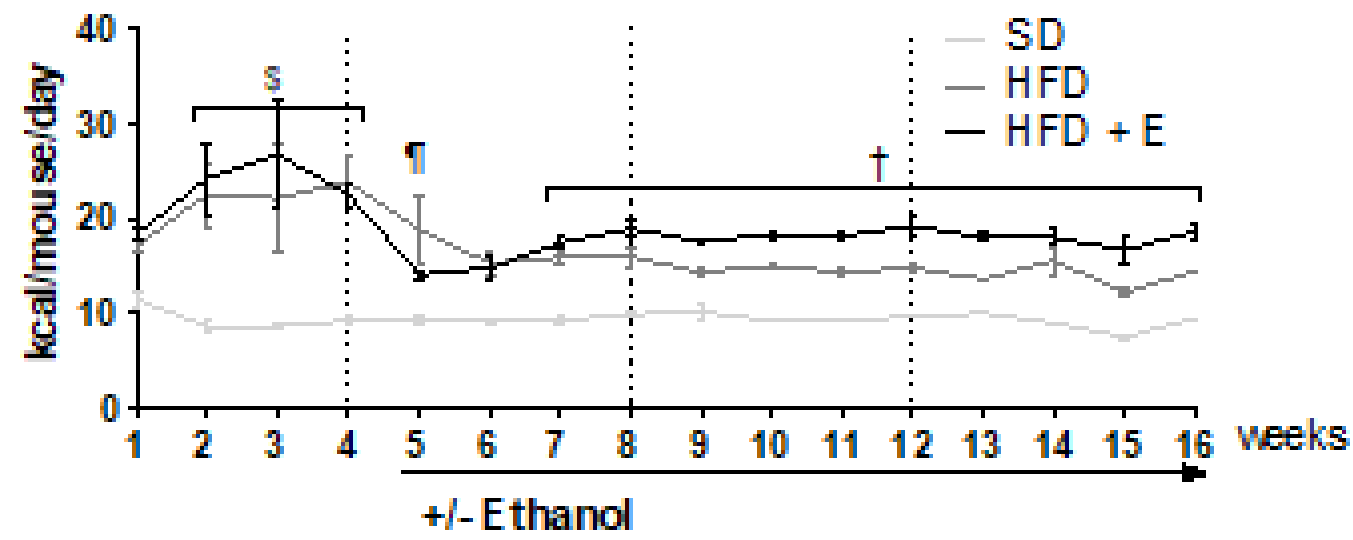

Figure 1 
721 Fig. 1. Body weight, body weight gain, food consumption and energy intake in mice fed the 722 standard diet (SD), mice fed the high-fat diet (HFD) and ethanol-treated HFD mice (HFD+E). (a) 723 Body weight (mean \pm SEM for 9-10 mice per group) was measured every week or two weeks (left 724 y-axis) and the body weight gain (right y-axis) was subsequently calculated. \$Significantly different 725 between HFD and SD mice, *significantly different between HFD+E and naive HFD mice, $\mathrm{p}<0.01$ 726 with a two-way ANOVA test. (b) Food consumption (mean \pm SEM for 9-10 mice per group) was 727 measured every week. ${ }^{\$}$ Significantly different between HFD and SD mice, $\mathrm{p}<0.05$ with a two-way 728 ANOVA test. (c) Energy intake (kcal/mouse/day) corresponding to food and ethanol (if any) 729 consumption in the different groups of animals (mean \pm SEM for 9-10 mice per group). 730 \$Significantly different between HFD and SD mice, "Significantly different between HFD and SD 731 mice, ${ }^{\dagger}$ Significantly different between HFD+E and SD mice, $\mathrm{p}<0.05$ with a two-way ANOVA test. 
a.

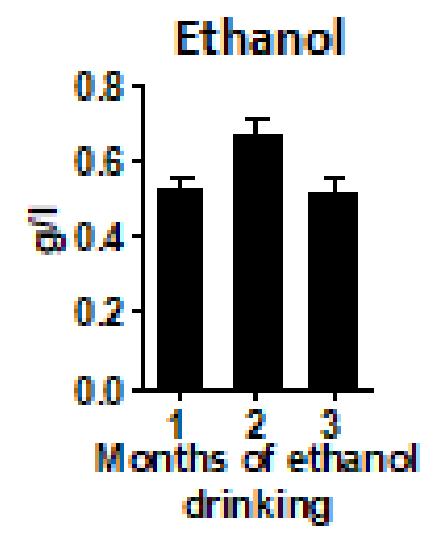

Triglycerides
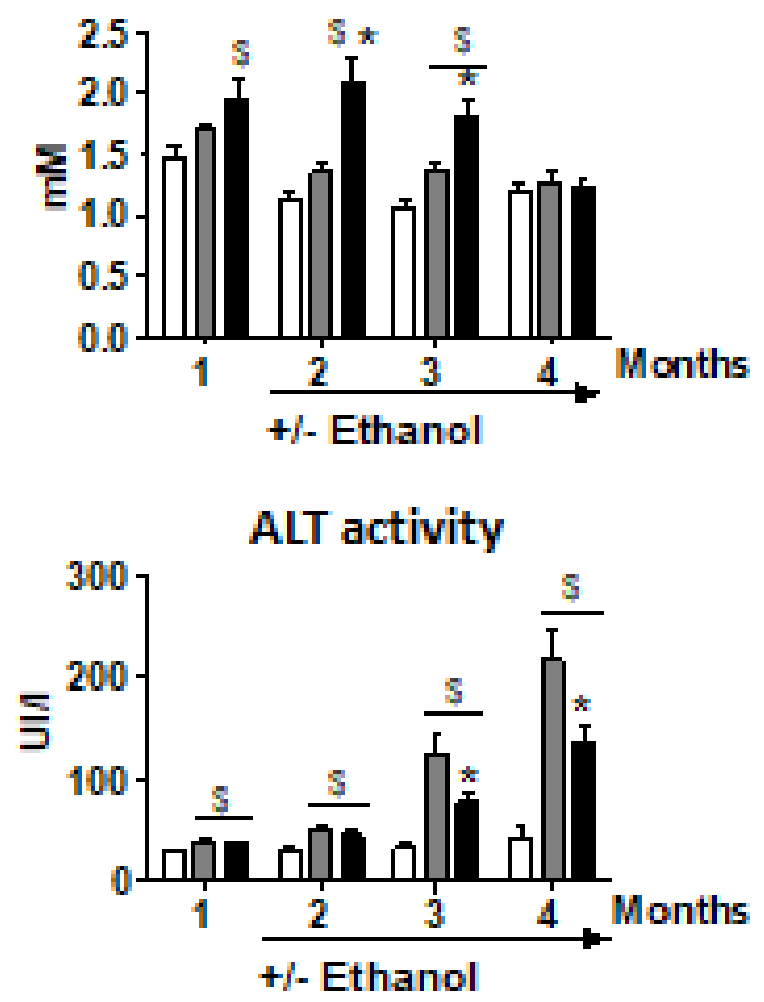

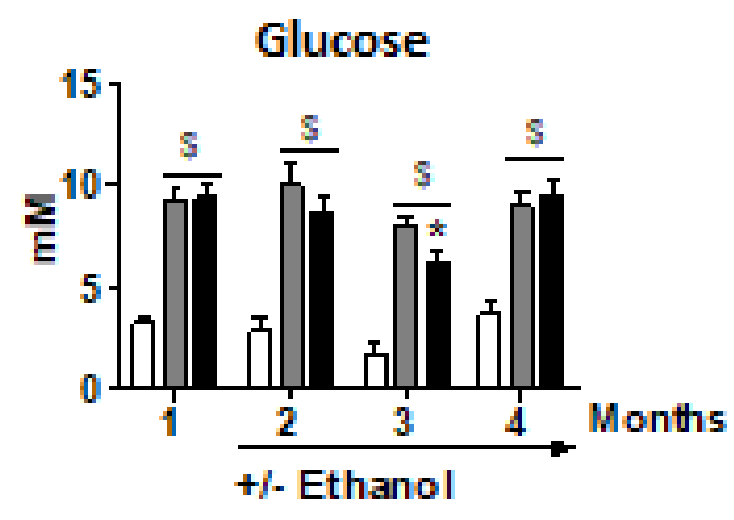

Total cholesterol

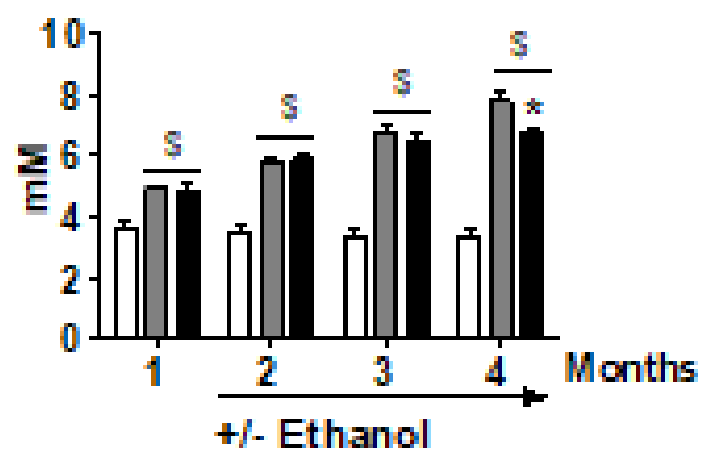

AST activity

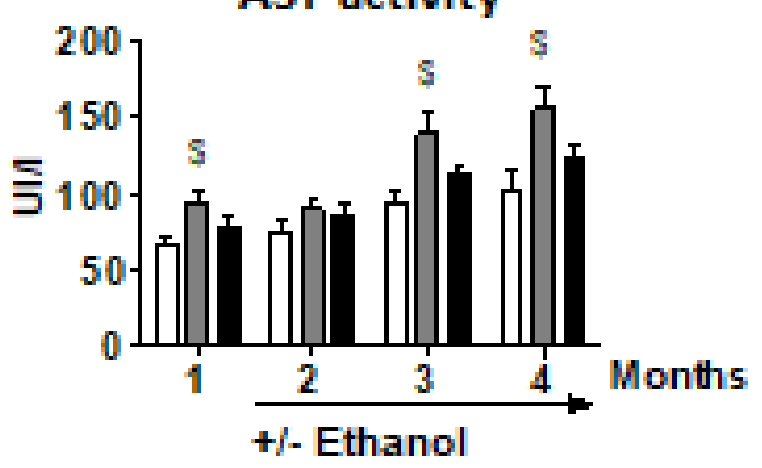

Mouse groups: $\square$ SD

HFD

$\mathrm{HFD}+\mathrm{E}$

b. Serum insulin serum adiponectin
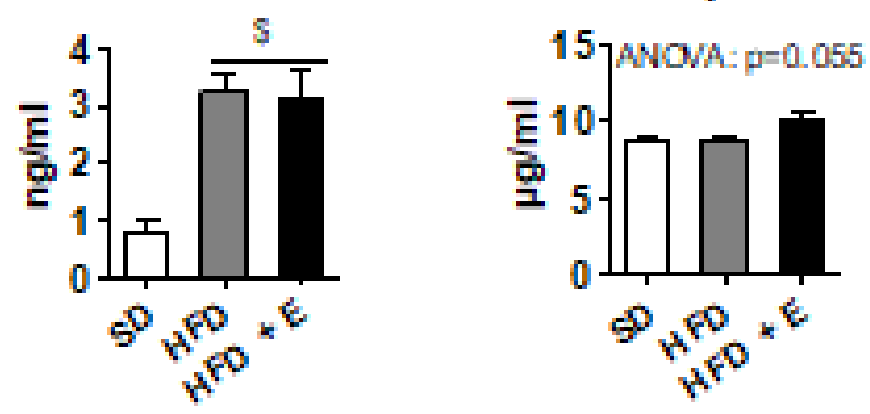

C. Liver weight

Figure 2

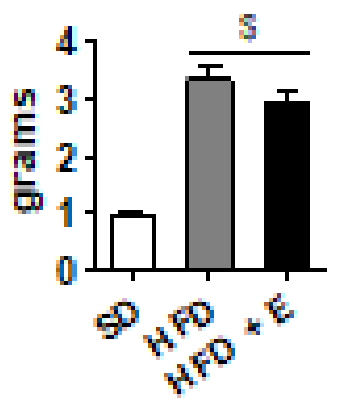


733 Fig. 2. (a) Serum parameters serially measured during the 4-month experiment in mice fed the 734 standard diet (SD), mice fed the high-fat diet (HFD) and ethanol-treated HFD mice (HFD+E). 735 Serum ethanol levels were measured only in the 10 ethanol-treated HFD mice. Values are means \pm 736 SEM for 8-10 mice per group for glucose, triglycerides and cholesterol and 7-10 mice per group for 737 alanine aminotransferase (ALT) and aspartate aminotransferase (AST) activities. \$Significantly 738 different from SD mice, *significantly different from naive HFD mice, $\mathrm{p}<0.05$ with a one-way 739 ANOVA test. (b) Serum insulin and adiponectin (mean \pm SEM for 7-10 mice per group) measured 740 at the end of the 4-month experiment. \$Significantly different from SD mice, $\mathrm{p}<0.001$ with a one741 way ANOVA test. (c) Liver weight (mean \pm SEM for 9-10 mice per group) measured at the end of 742 the 4-month experiment. ${ }^{\$}$ Significantly different from SD mice, $\mathrm{p}<0.001$ with a one-way ANOVA 743 test. 

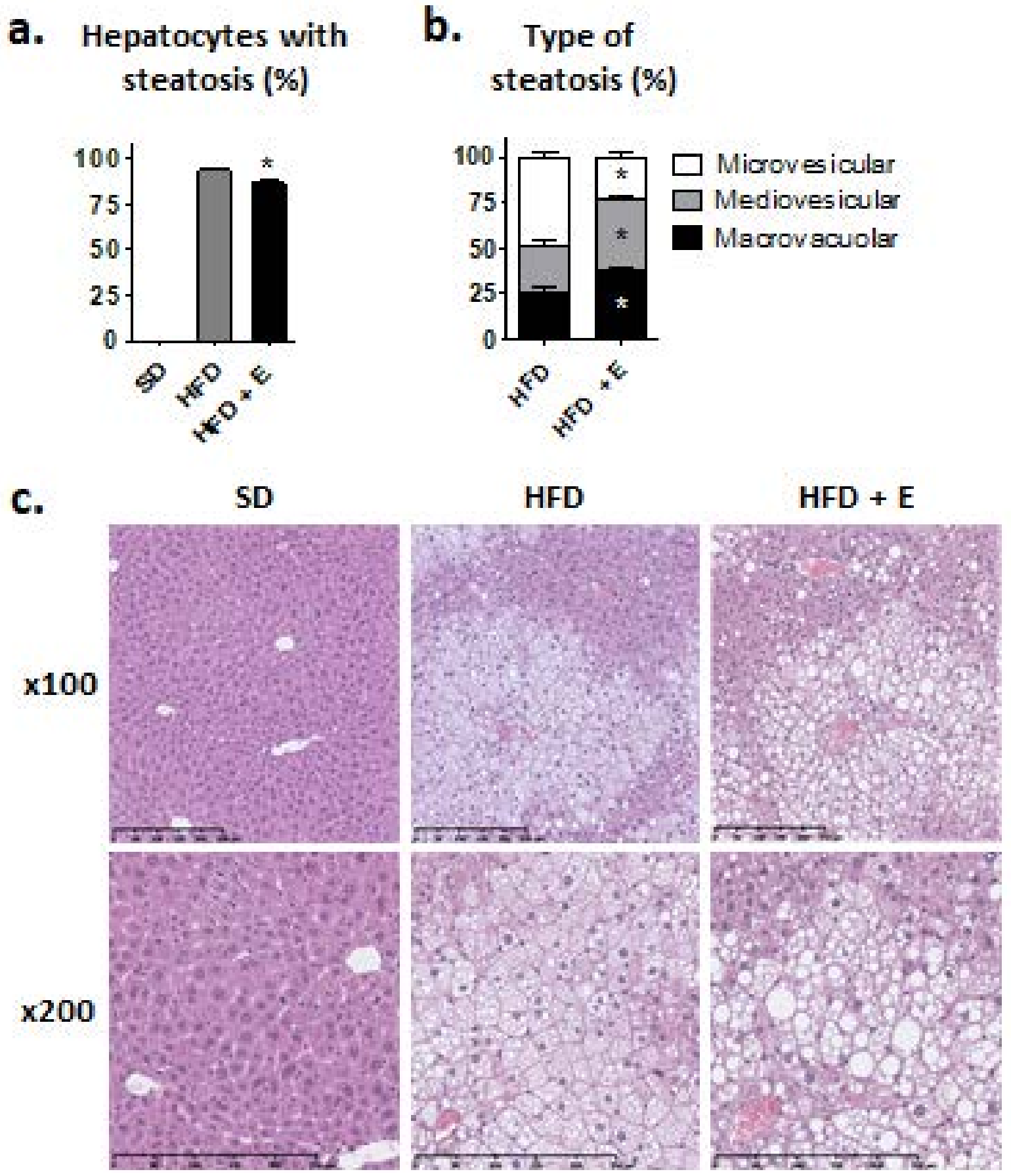

Figure 3 
745 Fig. 3. Features of hepatic steatosis in mice fed the standard diet (SD), mice fed the high-fat diet 746 (HFD) and ethanol-treated HFD mice (HFD+E). (a) Percentage of hepatocytes presenting steatosis. 747 Values are means \pm SEM for 9-10 mice per group. *Significantly different from naive HFD mice, $748 \mathrm{p}<0.01$ with a one-way ANOVA test. (b) Pattern of steatosis in HFD and HFD+E mice. Percentage 749 of steatotic hepatocytes presenting microvesicular, mediovesicular and macrovacuolar steatosis, 750 respectively. Values are means \pm SEM for 10 mice per group. *Significantly different from naive 751 HFD mice, $\mathrm{p}<0.01$ with a two-way ANOVA test. (c) Representative pictures of a naive SD mouse 752 liver with no steatosis, a naive HFD mouse liver with predominant microvesicular steatosis and an 753 ethanol-treated HFD mouse liver with predominant mediovesicular and macrovacuolar steatosis. 754 Sections were stained with HES and pictures were taken at 100x and 200x magnification, as 755 indicated. Scale bars $(250 \mu \mathrm{m})$ are indicated on each picture. 
$\begin{array}{lcc}\text { a. Perisinusoidal } & \begin{array}{c}\text { Portal fibrosis } \\ \text { fibrosis score }\end{array} & \text { b. Area of fibrosis } \\ \text { assessed with SHG (\%) }\end{array}$
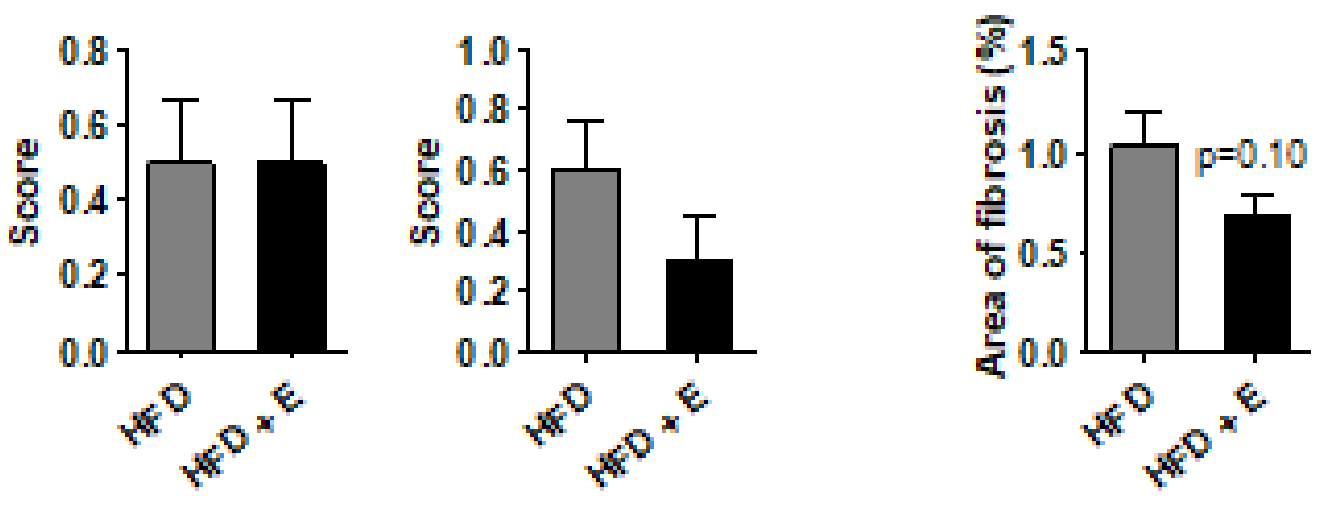

c.


Figure 4 
757 Fig. 4. Hepatic fibrosis in mice fed the high-fat diet (HFD) and ethanol-treated HFD mice 758 (HFD+E). (a) Score of perisinusoidal and portal fibrosis. Values are means \pm SEM for 10 mice per 759 group. (b) Percentage of area of fibrosis assessed by second-harmonic generation (SHG) 760 microscopy. Values are means \pm SEM for 10 mice per group, $\mathrm{p}=0.10$ with a $t$-test. (c) 761 Representative pictures of two naive HFD mouse livers and two HFD+E mouse livers with less 762 portal fibrosis. Scale bars $(250 \mu \mathrm{m})$ are indicated on each picture. 
a. Mass of fatty acids
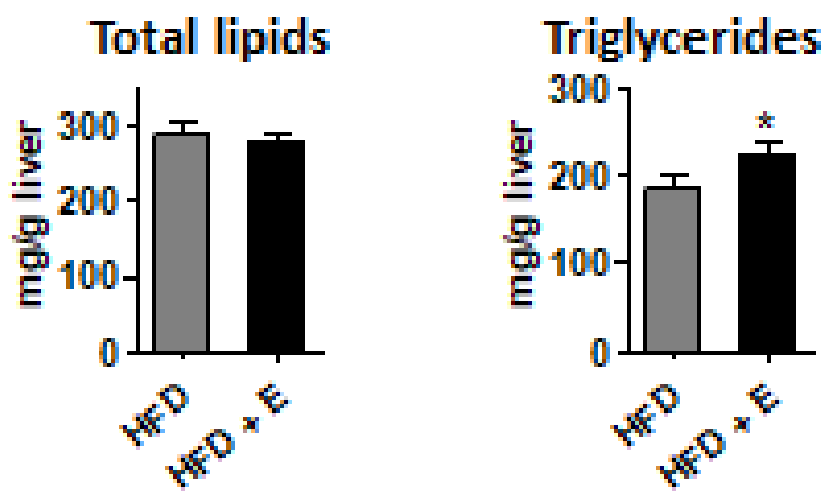

Phospholipids

b. Proportion of fatty acids in total lipids



SFA

MUFA

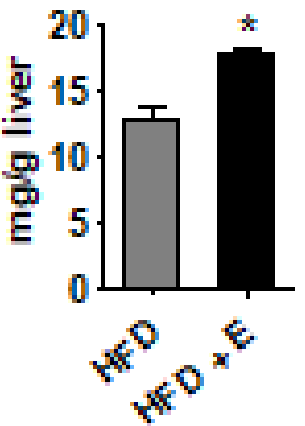

c. $\Delta 9$-Desaturation index
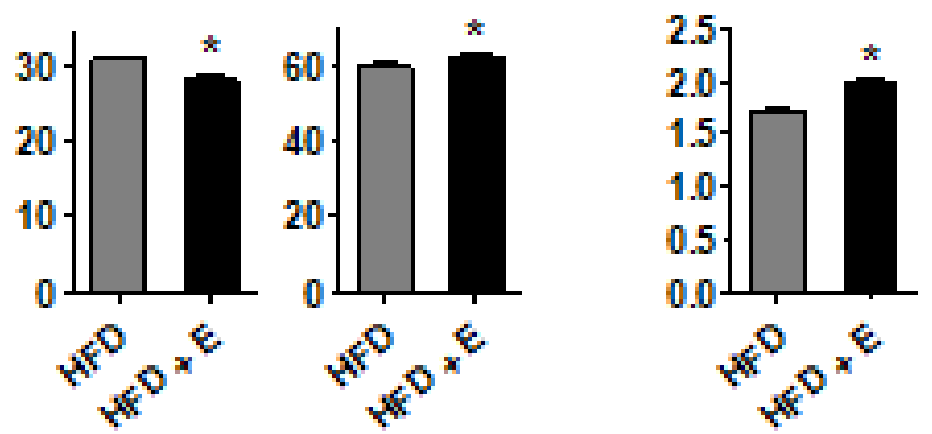

d. Expression of genes involved in glycolysis and lipogenesis

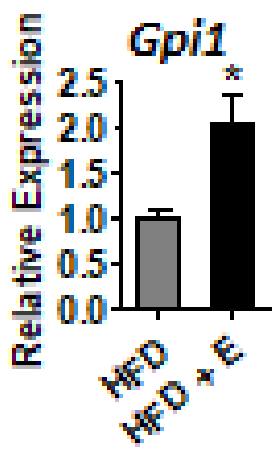

Aldob

Pklr

Pdhb

Acly

Acaca
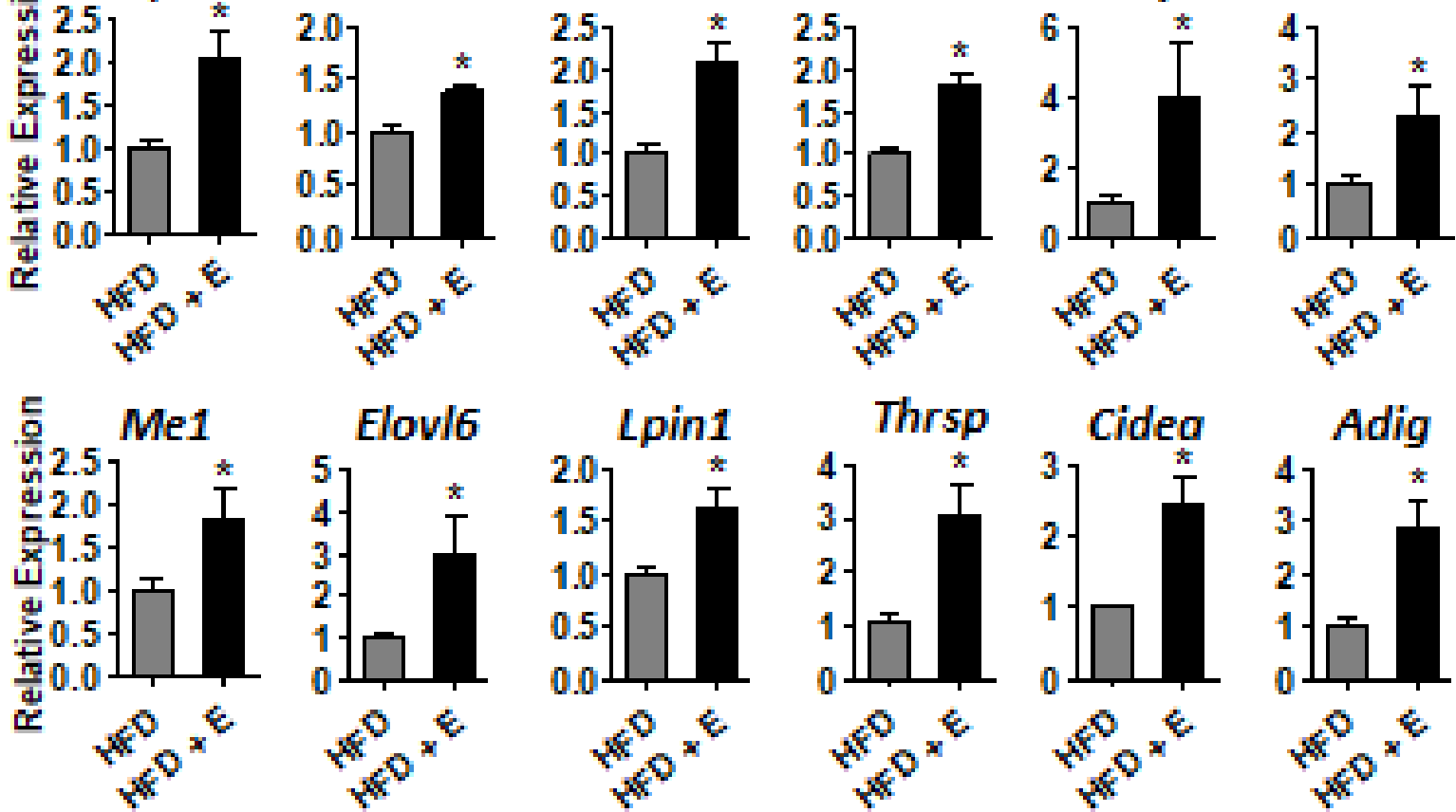

$6^{\circ}{ }^{*}$


Figure 5 
764 Fig. 5. Analysis of hepatic fatty acids in high-fat diet (HFD) and ethanol-treated HFD mice 765 (HFD+E). (a) Mass of fatty acids from total lipids and in the triglyceride and phospholipid 766 fractions. Values are means \pm SEM for 10 mice per group. *Significantly different from naive HFD 767 mice, $\mathrm{p}<0.05$ with a $t$-test. (b) Proportion of palmitic acid (C16:0), oleic acid (C18:1 n-9), saturated 768 fatty acids (SFAs) and monounsaturated fatty acids (MUFAs) in total lipids. Values are means \pm 769 SEM for 10 mice per group. *Significantly different from naive HFD mice, $\mathrm{p}<0.05$ with a $t$-test. (c) $770 \Delta$ 9-Desaturation index calculated as the ratio $(\mathrm{C} 16: 1 \mathrm{n}-7+\mathrm{C} 18: 1 \mathrm{n}-9) /(\mathrm{C} 16: 0+\mathrm{C} 18: 0)$. Values are 771 means \pm SEM for 10 mice per group. *Significantly different from naive HFD mice, $\mathrm{p}<0.05$ with a 772 t-test. (d) Hepatic mRNA levels of genes involved in glycolysis and lipogenesis extracted from the 773 transcriptomic analysis (GSE116417). Values are means \pm SEM for 5 mice per group. 774 *Significantly different from naive HFD mice, $\mathrm{p}<0.05$ with a Mann-Whitney test. 
a.

a. GO: Collagen fibril organization

땀요

突 -0.2

$-04$

+05 NCS: -2.827

4 05 NOKI p-val: 0.000

E -07 FDA q-val: 0.000

는
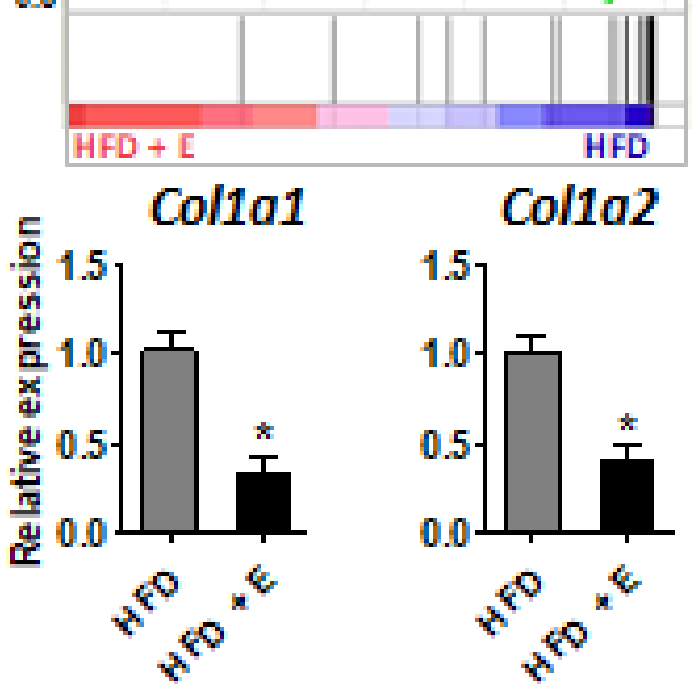

b.
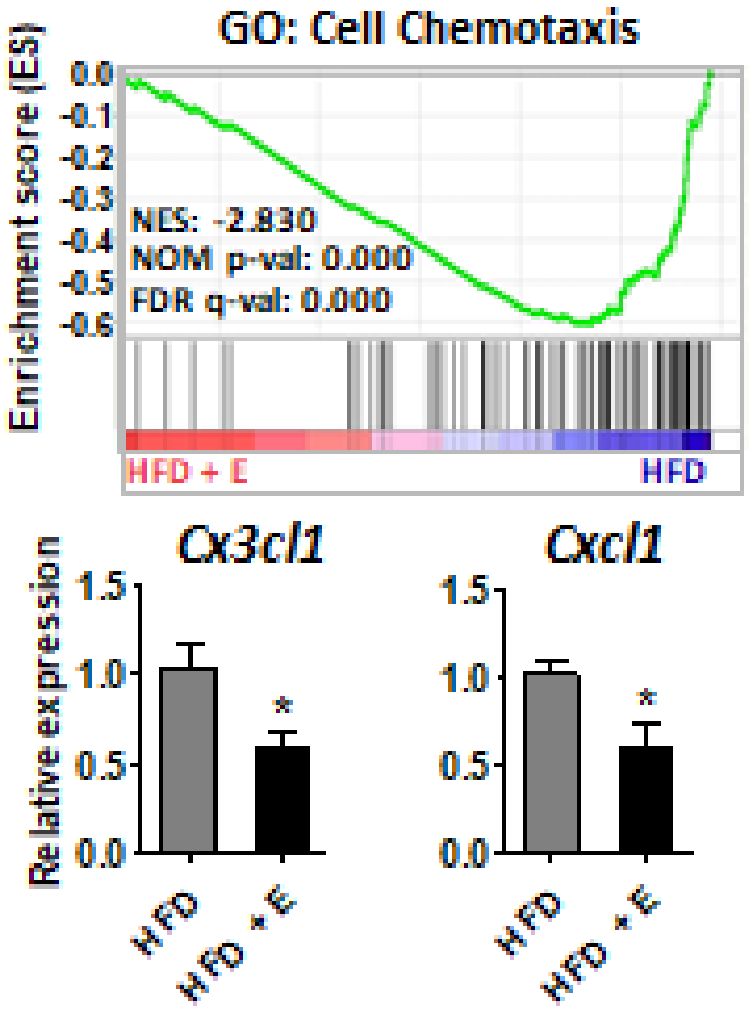

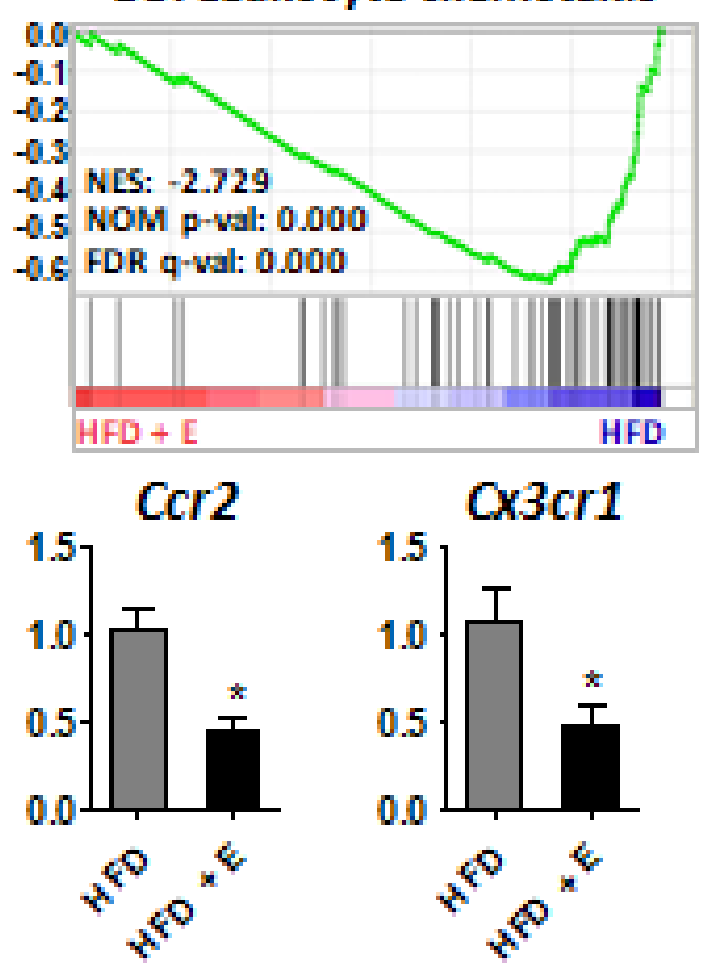

Figure 6 
776 Fig. 6. mRNA expression of hepatic genes involved in fibrosis and cell chemotaxis in high-fat diet 777 (HFD) and ethanol-treated HFD mice (HFD+E). Genome-wide expression profiling performed in 778 naive $(n=5)$ and ethanol-treated $(n=5)$ HFD mice (GSE116417) was used for subsequent gene set 779 enrichment analysis (GSEA). (a) GSEA revealing in naive HFD mice a significant enrichment of 780 the gene ontology (GO) gene sets corresponding to "collagen fibril organization” and "extracellular 781 structure organization", in comparison with ethanol-treated HFD mice. The hepatic mRNA 782 expression of 4 representative genes involved in fibrosis, extracted from the transcriptomic analysis 783 (GSE116417), is shown below the GSEA plots. *Significantly different from naive HFD mice, $784 \mathrm{p}<0.05$ with a Mann-Whitney test. (b) GSEA revealing in naive HFD mice a significant enrichment 785 of the GO gene sets related to "cell chemotaxis” and "leukocyte chemotaxis", in comparison with 786 ethanol-treated HFD mice. The hepatic mRNA expression of 4 representative genes involved in cell 787 chemotaxis, extracted from the transcriptomic analysis (GSE116417), is shown below the GSEA 788 plots. *Significantly different from naive HFD mice, $\mathrm{p}<0.05$ with a Mann-Whitney test. 
a. GO: Oxydative phosphorylation
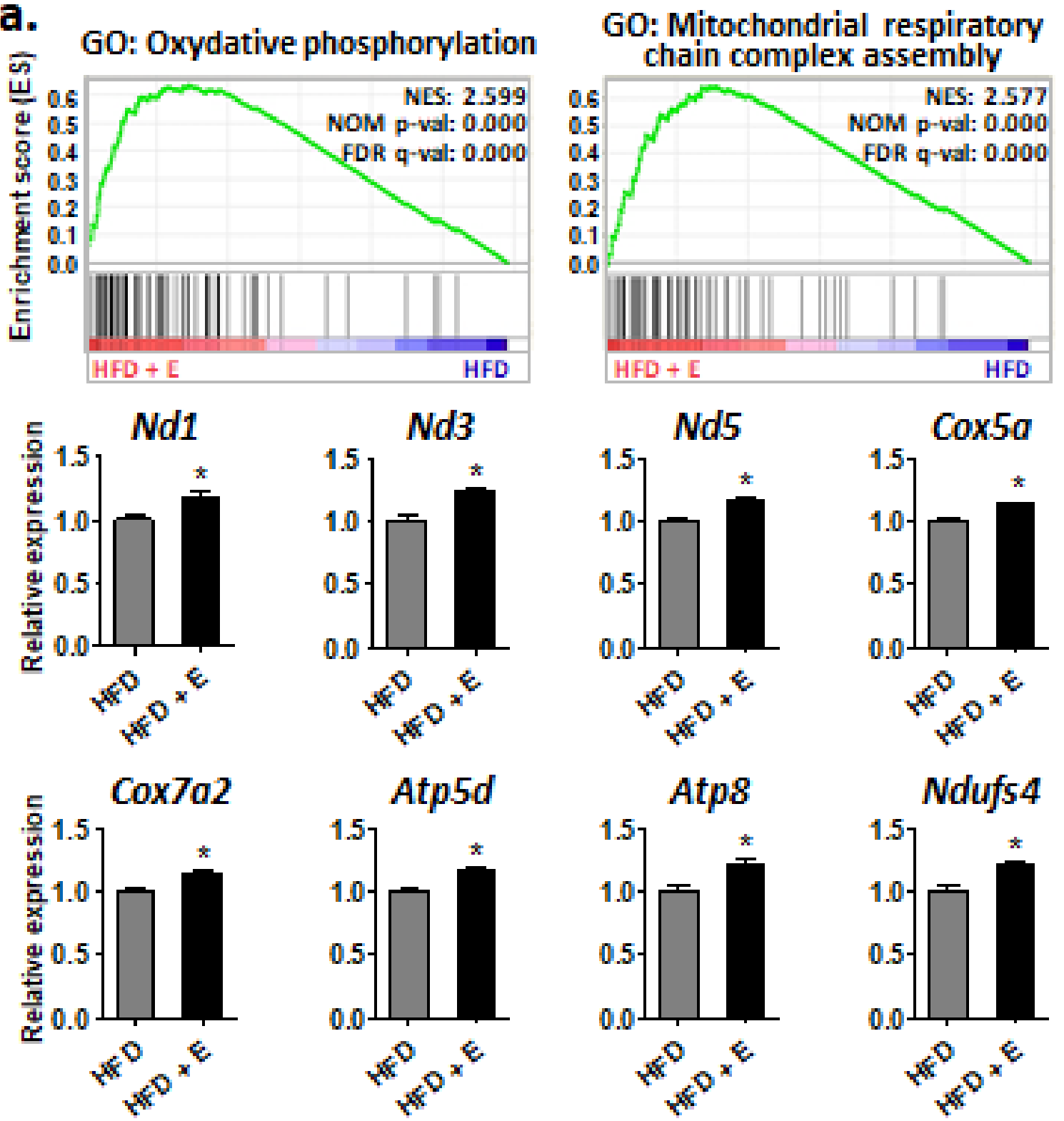

b.

Complex I activity

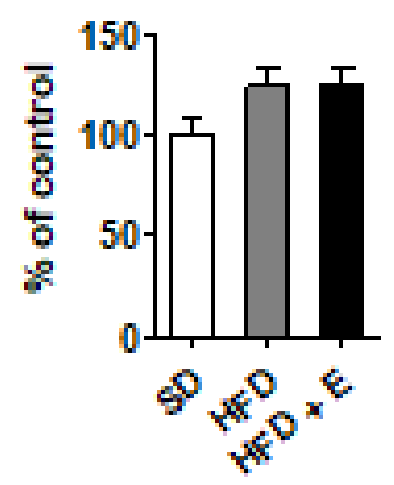

Figure 7

Complex II activity

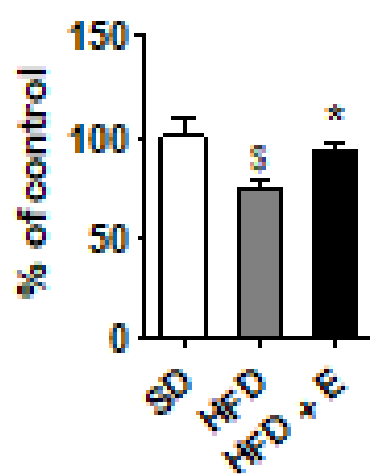


790 Fig. 7. mRNA expression of hepatic genes involved in mitochondrial function and mitochondrial 791 respiratory chain (MRC) complex I and II activities in high-fat diet (HFD) and ethanol-treated HFD 792 mice (HFD+E). (a) Genome-wide expression profiling performed in naive ( $\mathrm{n}=5)$ and ethanol-treated 793 (n=5) HFD mice (GSE116417) was used for subsequent gene set enrichment analysis (GSEA). 794 GSEA showing in ethanol-treated HFD a significant enrichment of the gene ontology (GO) gene 795 sets corresponding to “oxidative phosphorylation” (OXPHOS) and "MRC complex assembly", 796 compared with naive HFD mice. The hepatic mRNA expression of 8 representative genes involved 797 in oxidative phosphorylation and MRC complex assembly, extracted from the transcriptomic 798 analysis (GSE116417), is shown below the GSEA plots. *Significantly different from naive HFD 799 mice, $\mathrm{p}<0.05$ with a Mann-Whitney test. (b) MRC complex I and II activities. Values are means \pm 800 SEM for 9-10 mice per group. ${ }^{\$}$ Significantly different from SD mice, *significantly different from 801 naive HFD mice, $\mathrm{p}<0.05$ with a one-way ANOVA test. 
a. Total GSH GSSG/GSH $\begin{gathered}\text { Carbonylated } \\ \text { proteins }\end{gathered}$ MDA levels
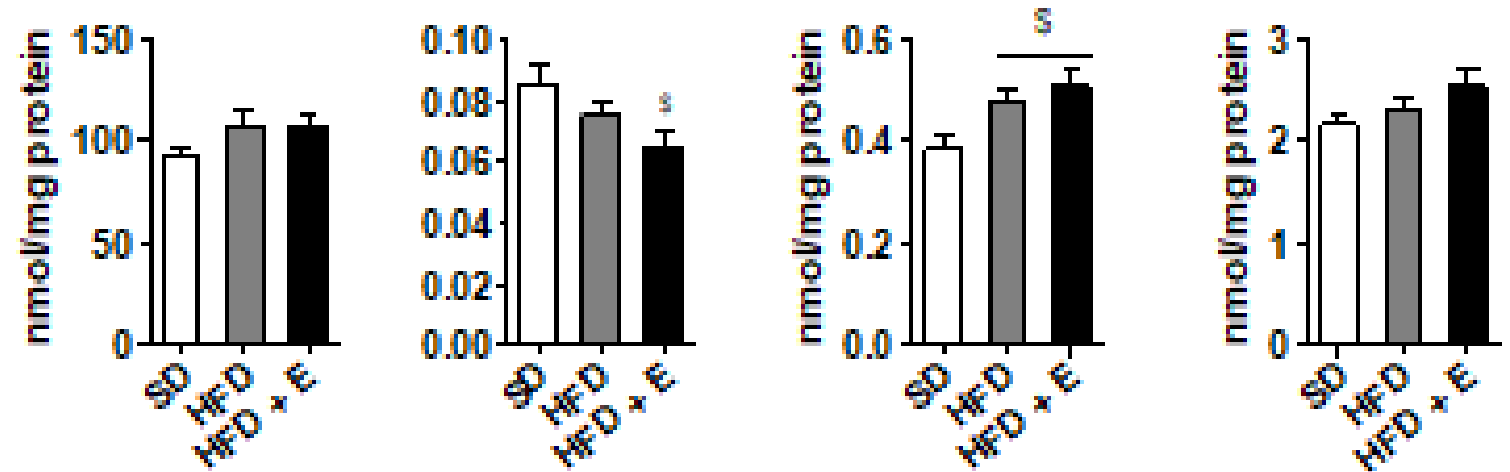

b. CYP2E1 protein expression

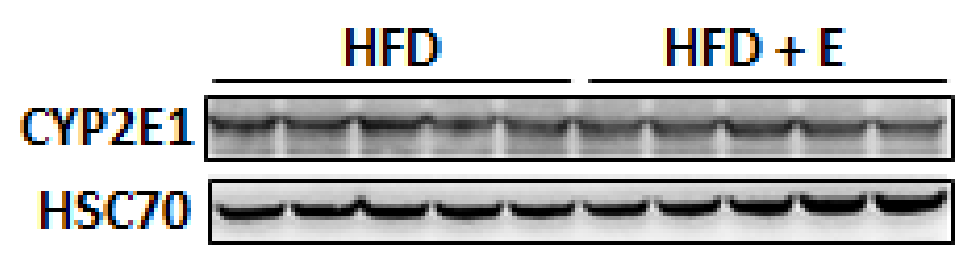

CYP2E1/HSC70 ratio

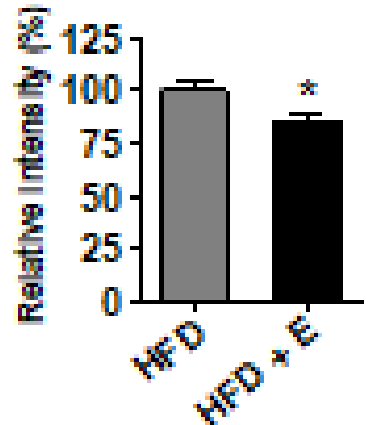

c.
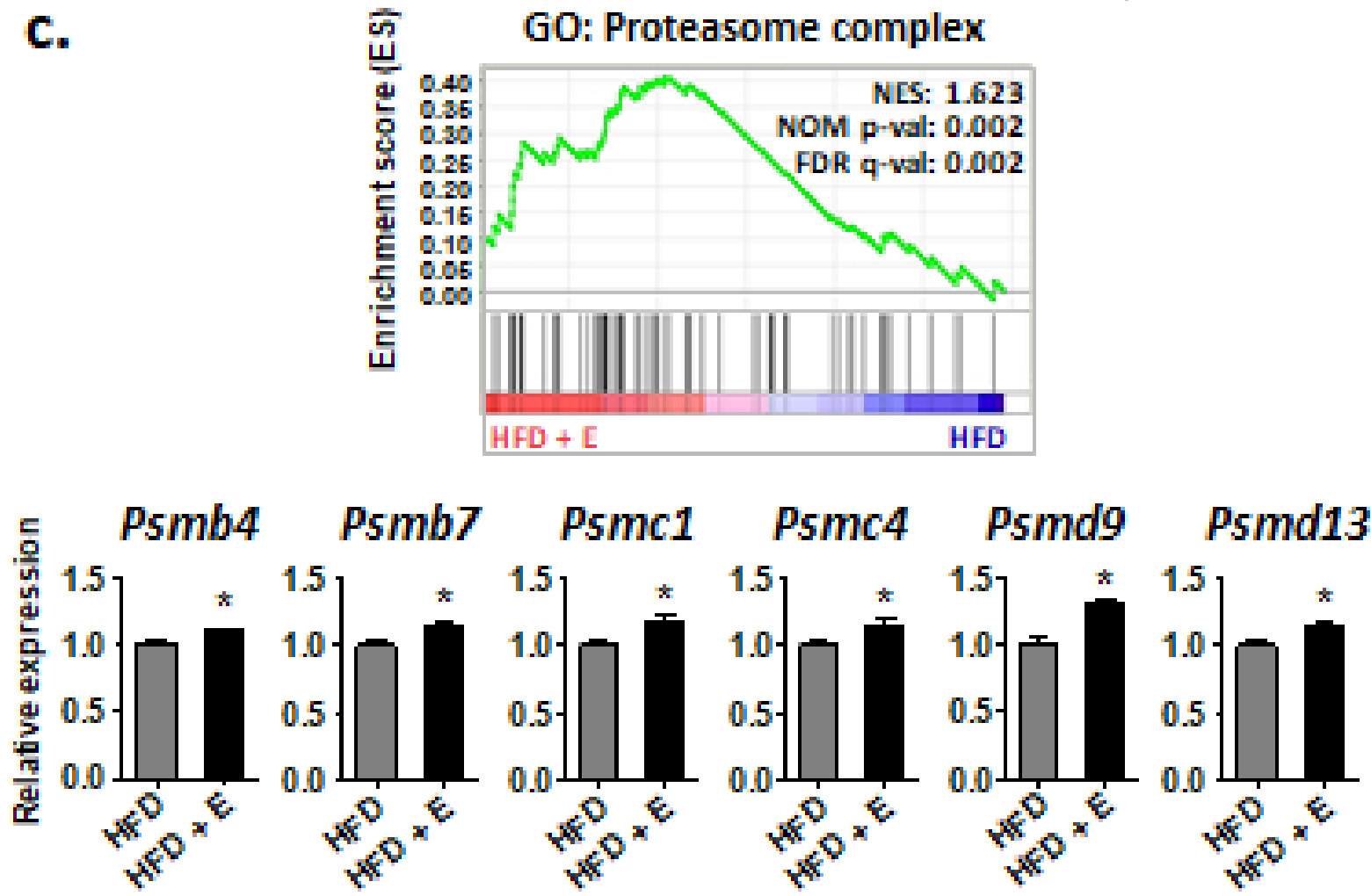

Figure 8 
Fig. 8. Markers of hepatic oxidative stress and cellular defense systems in mice fed the standard diet (SD), mice fed the high-fat diet (HFD) and ethanol-treated HFD mice (HFD+E). (a) Total glutathione, namely reduced glutathione (GSH) plus oxidized glutathione (GSSG), GSSG/GSH ratio and carbonylated proteins and levels of malondialdehyde (MDA). Values are means \pm SEM for 9-10 mice per group for GSH and carbonylated proteins and 7-10 mice per group for MDA levels. ${ }^{\$}$ Significantly different from SD mice, $\mathrm{p}<0.05$ with a $t$-test. (b) Protein expression of cytochrome P450 2E1 (CYP2E1) and heat shock cognate 70 (HSC70), used as loading control. Representative western blot for 5 mice per group. CYP2E1/HSC70 ratios showed in the graph are means \pm SEM for 10 mice per group. *Significantly different from naive HFD mice, $\mathrm{p}<0.05$ with a t-test. (c) Gene set enrichment analysis (GSEA) showing in ethanol-treated HFD a significant enrichment of the gene ontology (GO) gene set corresponding to the "proteasome complex", compared with naive HFD mice. The hepatic mRNA expression of 6 representative genes involved in the proteasome complex, extracted from the transcriptomic analysis (GSE116417), is shown below the GSEA plots. Values are means \pm SEM for 5 mice per group. *Significantly different from naive HFD mice, $\mathrm{p}<0.05$ with a Mann-Whitney test. 